\title{
Underwater Acoustic Measurements to Estimate Wind and Rainfall in the Mediterranean Sea
}

\author{
Sara Pensieri, ${ }^{1}$ Roberto Bozzano, ${ }^{1}$ Jeffrey A. Nystuen, ${ }^{2}$ Emmanouil N. Anagnostou, ${ }^{3}$ \\ Marios N. Anagnostou, ${ }^{4}$ and Renzo Bechini ${ }^{5}$ \\ ${ }^{1}$ National Research Council of Italy, Via de Marini 6, 16149 Genoa, Italy \\ ${ }^{2}$ Applied Physics Laboratory, University of Washington, 1013 NE 40th Street, Seattle, WA 98105, USA \\ ${ }^{3}$ Civil and Environmental Engineering, University of Connecticut, 261 Glenbrook Road, Unit 3037, Storrs, CT 06269, USA \\ ${ }^{4}$ National Observatory of Athens, P.O. Box 20048, Thissio, 11810 Athens, Greece \\ ${ }^{5}$ Agenzia Regionale per la Protezione Ambientale Piemonte, Via Pio VII 9, 10135 Turin, Italy \\ Correspondence should be addressed to Sara Pensieri; sara.pensieri@ge.issia.cnr.it
}

Received 1 December 2014; Accepted 10 March 2015

Academic Editor: Hiroyuki Hashiguchi

Copyright (c) 2015 Sara Pensieri et al. This is an open access article distributed under the Creative Commons Attribution License, which permits unrestricted use, distribution, and reproduction in any medium, provided the original work is properly cited.

\begin{abstract}
Oceanic ambient noise measurements can be analyzed to obtain qualitative and quantitative information about wind and rainfall phenomena over the ocean filling the existing gap of reliable meteorological observations at sea. The Ligurian Sea Acoustic Experiment was designed to collect long-term synergistic observations from a passive acoustic recorder and surface sensors (i.e., buoy mounted rain gauge and anemometer and weather radar) to support error analysis of rainfall rate and wind speed quantification techniques developed in past studies. The study period included combination of high and low wind and rainfall episodes and two storm events that caused two floods in the vicinity of La Spezia and in the city of Genoa in 2011. The availability of high resolution in situ meteorological data allows improving data processing technique to detect and especially to provide effective estimates of wind and rainfall at sea. Results show a very good correspondence between estimates provided by passive acoustic recorder algorithm and in situ observations for both rainfall and wind phenomena and demonstrate the potential of using measurements provided by passive acoustic instruments in open sea for early warning of approaching coastal storms, which for the Mediterranean coastal areas constitutes one of the main causes of recurrent floods.
\end{abstract}

\section{Introduction}

Ocean ambient noise plays a basic role in the studies of both marine acoustics and acoustical oceanography and the need to better understand the impacts of human activities on the ecology of marine mammals puts new emphasis on its analysis in order to protect the ecosystem.

Preliminary studies of underwater ambient noise were carried out during the World War II and were covering a wide range of conditions and locations. They established that noise radiated from ships and sounds produced by breaking waves on sea surface and by marine animals contribute to ambient noise. After few years Wenz [1] demonstrated that ships across ocean generate a background noise at very low frequencies and his curves formed the basis of several prediction systems.
A new definition of ambient noise was introduced in 2003 by the National Research Council's report [2] that described it as "noise associated with the background din emanating from a myriad of unidentified sources."

Recently, the Marine Framework Strategy Directive (MFSD) acknowledges underwater noise as a pollutant and, as descriptor 11, states the need for monitoring the "Introduction of energy, including underwater noise" so that it "is at levels that do not adversely affect the marine environment" [3]. Since the issuing of the MFSD, for most of the descriptors, the European Commission released specific regulations providing guiding rules to implement the monitoring tasks: other descriptors (namely, marine litter and energy into the water) were initially not considered, so mature and technical working groups were created to further develop the descriptors 
and to provide the necessary regulations. They were finally published in 2011 for the marine litter and in 2012 for the underwater noise.

Underwater ambient noise measured by hydrophones depends on both the strength and concentration of the sources and the propagation of sound from the sources to the receiver, which is influenced by environmental conditions (i.e., oceanographic dynamics, sound velocity profile, and bathymetry). All these properties could cause fluctuations in the sound pressure levels (SPL) of ambient noise and since they change in accordance with depth, time, and location it is necessary to carry out experiments to improve the quantification of sound sources from ambient noise measurements.

Furthermore, the objective of preserving the biodiversity and encouraging policies devoted to a sustainable use of marine resources has drawn attention and highlighted the need for an intense monitoring of underwater noise level [4] and, consequently, for the development of innovative sensors [5] and networks [6-8] able to collect and analyze long-term underwater sound data.

Passive underwater acoustics can significantly contribute to the monitoring of the oceanic environment, since sound sources can be distinguished on the basis of their acoustic signatures and the main categories of sound that contribute to ambient noise can be identified into physical, biological, and anthropogenic.

Since ocean is coupled to land and atmosphere, the prevailing physical sources of natural sounds can be detected at the interfaces between the cited media, but the other noise originated into atmosphere penetrates into the sea.

Wind blowing over the sea is the most common physical phenomenon producing sound at sea surface and its spectral characteristics cover a wide frequency band $(1 \mathrm{~Hz}-50 \mathrm{kHz})$ showing approximately parallel curves proportional to the reinforcement of wind speed [9].

Sound generated by light and moderate wind is the most ubiquitous noise condition in the ocean whereas high wind episodes represent a difficult phenomenon to be identified by the produced sound due to potential ambiguity with ship noise. Wind speeds over $10 \mathrm{~m} / \mathrm{s}$ are often associated with wave breaking generating small bubbles that splashed into the ocean absorbing sound from new breaking waves; thus the sound levels at frequency over $10 \mathrm{kHz}$ result is lower than that for light wind [10].

Precipitation events on the ocean contribute to ambient noise in the frequency band between several hundred of Hertz to more than $20 \mathrm{kHz}$ depending on rainfall type [11]: light precipitation (associated with drops smaller than $0.5 \mathrm{~mm}$ in diameter, defined as drizzle hereafter), stratiform rain (simply called rain hereafter), and heavy rain (intense and short-duration phenomena, called convective hereafter) events.

In case of drizzle, the correspondent spectra are characterized by a peak at about $15 \mathrm{kHz}$ due to the acoustic resonance generated from small drops that splashed consistently [12]. This peak tends to reduce with the increasing of rainfall rate associated with big drops that produce sound below $10 \mathrm{kHz}$ and a peak in the frequency band between $1 \mathrm{kHz}$ and $2 \mathrm{kHz}$ in case of convective rain. Rainfall phenomena can be distinguished from wind by the sound produced on sea surface since precipitation spectra show more high frequency sounds and are louder when compared with wind.

Recently, some studies were carried out by deploying cabled, floating, suspended, or self-recording hydrophones [13-15], but few acoustic sensors were designed to process acoustic data in near real time.

The Applied Physics Laboratory of the University of Washington developed the Passive Aquatic Listener (named PAL, hereafter) a compact sensor able to use the underwater sound field to detect and monitor rainfall at sea [16].

PALs were successfully deployed on moorings in different basins [17-19] and on ARGO floats [20] and their classification and quantification algorithms were validated by means of radar estimates and in situ hourly averaged wind speed data.

In order to assess the performance of PALs in a different environmental setup and with the availability of high resolution (5 seconds) in situ wind speed and rainfall observations, the Ligurian Sea Acoustic Experiment (LiSAE) was carried out.

More than one year of measurements were collected deploying a PAL on board the Eulerian "Western 1-Mediterranean Moored Multisensor Array" (W1M3A, hereafter) observing system, part of the European network of fixed deepocean stations $\left(\mathrm{FixO}^{3}\right)$ [21] and of the Italian ocean observing system which is under development within the framework of the National Group for Operational Oceanography.

The acoustic data collected in this experiment were validated through direct comparison with in situ observations acquired by the W1M3A observatory and a coastal weather radar.

The paper describes the analysis of the data collected during LiSAE and proposes an enhancement of the already existing algorithms to detect and quantify rain and wind at sea for the monitoring of these physical phenomena in the Ligurian basin.

The paper is subdivided into the following sections: Section 2 describes the experimental setup, Section 3 explains the dataset and the methodology and discusses the results. In the last section, summary and conclusions are given.

\section{Setup and Environmental Conditions of the Experiment}

The experiment took place from June 2011 to May 2012 in the Ligurian Sea, the northwestern part of the Mediterranean Sea that together with the Gulf of Lion represents a major component of the overall Mediterranean energy budget [22].

The complex coastal topography with mountains close to the sea and the presence of Corsica island are responsible for the regional changes of wind field and frontal systems associated with low pressure that give origin to gale and near gale winds [23].

The Ligurian basin is also an ideal area for monitoring water and heat flux exchanges [24] and it is characterized by the formation of dense water that influences the circulation of the deepest layers of the Mediterranean Sea and the formation 


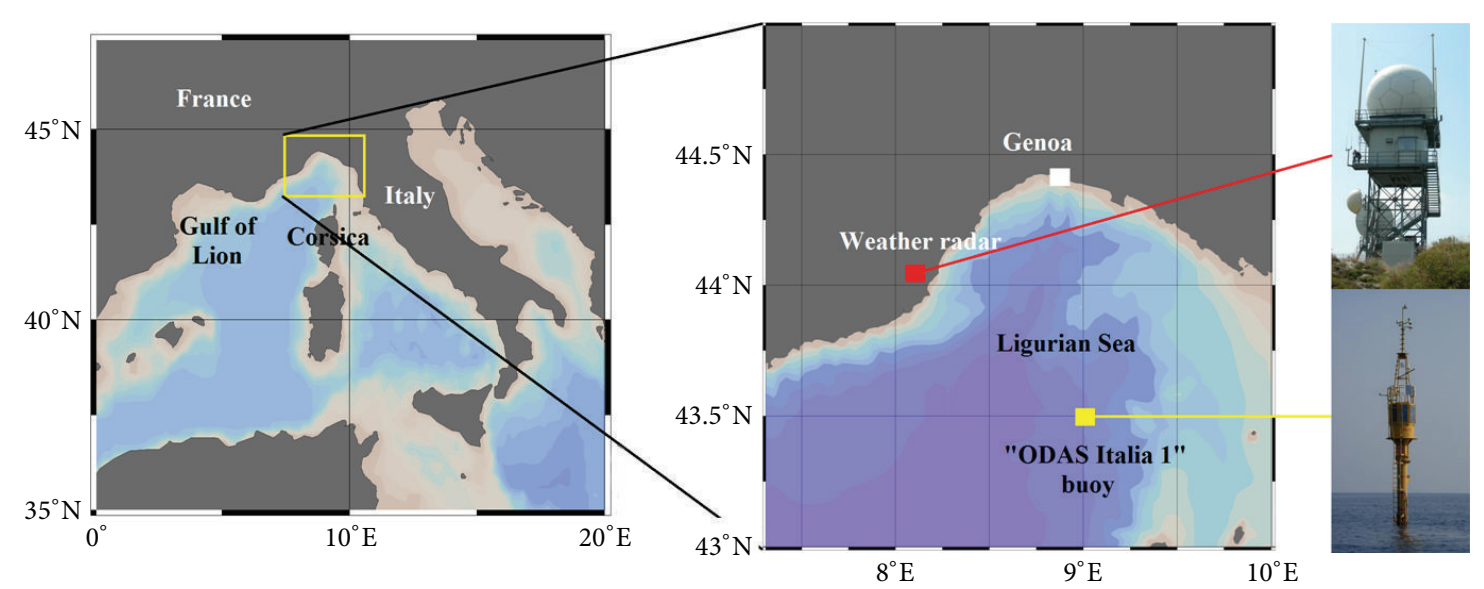

FIGURE 1: Map of the working area of the LiSAE experiment and zoom indicating the position of the weather radar and the "ODAS Italia 1" buoy.

of atmospheric cyclogenesis that sometimes give rise to floods in the Ligurian and Tuscany coasts $[25,26]$.

In late summer and early autumn, the strong and highly humid perturbations that reach the basin from the south along with the fact that coasts are strongly urbanized and industrialized determine a high flood hazard period. Since the 60's, with impressive regularity, about 40 heavy flash floods have occurred in the region with severe damages to infrastructure and loss of lives.

The Ligurian Sea Acoustic Experiment dealt with precipitation estimates from a coastal weather radar coupled with operational underwater acoustical and high resolution in-situ meteorological observations provided by the meteooceanographic observatory W1M3A composed of the "ODAS Italia 1 " spar buoy and a nearby subsurface mooring (Figure 1).

The experimental setup was completed by the deployment of a PAL that was clamped to the body of the "ODAS Italia 1" buoy at the deepest possible depth $(36 \mathrm{~m})$ in order to obtain real-time data by means of a cable running along the buoy body up to the small laboratory in the upper part of the observatory.

A two-way communication protocol was developed to retrieve real-time underwater acoustics data from the PAL whose acoustic measurements were integrated in the existing data streaming of the observatory to make them available to the receiving station in near real time. Data transmission from the buoy to the station ashore was guaranteed by an IRIDIUM satellite link.

In the design of the experiment, particular attention was paid to ensure that the chosen position for the installation was free from interferences due to preexistent oceanographic payload of the buoy (echo-sounders, ADCP).

The deployment of PAL at $36 \mathrm{~m}$ depth during LiSAE experiment implied a footprint at the surface of about $100 \mathrm{~m}$ since Anagnostou et al. [19] demonstrated that the real listening area of a PAL is proportional to approximately three times the deployment depth.

During the experiment, the most frequent measured wind speed value was about $2.5 \mathrm{~m} / \mathrm{s}$; wind speeds over $20 \mathrm{~m} / \mathrm{s}$ were recorded during the storms that occurred between October 2011 and February 2012, while moderate winds (between $15 \mathrm{~m} / \mathrm{s}$ and $20 \mathrm{~m} / \mathrm{s}$ ) were observed in July 2011 and in the fall season of 2011-2012. The in situ observations confirmed the seasonal trend of the wind field of the Ligurian basin derived from buoy data in the period 2000-2014 (Figure 2) with a prevailing wind regime characterized by calm and light winds and a wind vector extremely variable.

Two high precipitation events occurred in the period of the experiment: the first on the 25th of October 2011 and the second on the 4th and 5th of November 2011. In October the most intense phenomena occurred near La Spezia, where 13 people died and more than 50 were evacuated due to the overflow of the torrents in the nearby basin of Levanto and Vernazza and of the effluent of Magra river. In the 4th to 5 th of November flood in Genoa, 6 people died due to the overflow of the torrent Fereggiano, and more than 100 people were evacuated while large flooding caused the isolation of large parts of the city.

2.1. Passive Aquatic Listener (PAL). The Passive Aquatic Listener device has been designed to monitor and interpret ambient noise in real time and on long-term basis performing on-board processing to distinguish the different sound sources and then quantitatively estimate wind speed and rainfall rate.

The core of the sensor consists of a low noise wideband hydrophone with a sensitivity of $-160 \mathrm{~dB}$ relative to $1 \mathrm{~V} / \mu \mathrm{Pa}$ and a resonance frequency of $40 \mathrm{kHz}$. Second-order bandpass filters are present in order to reduce both saturation from low frequency sound $(<20 \mathrm{~Hz})$ and aliasing from above $50 \mathrm{kHz}$. A low noise amplifier, a single signal processing board, a low power processor with A/D digitizer at $100 \mathrm{kHz}$, a flash memory of 2 Gbytes, and a battery pack complete the instrument ensemble.

The sensor records ambient noise with an adaptive sampling strategy based on the detection of wind and different rainfall types (drizzle, rain, and convective rain). 


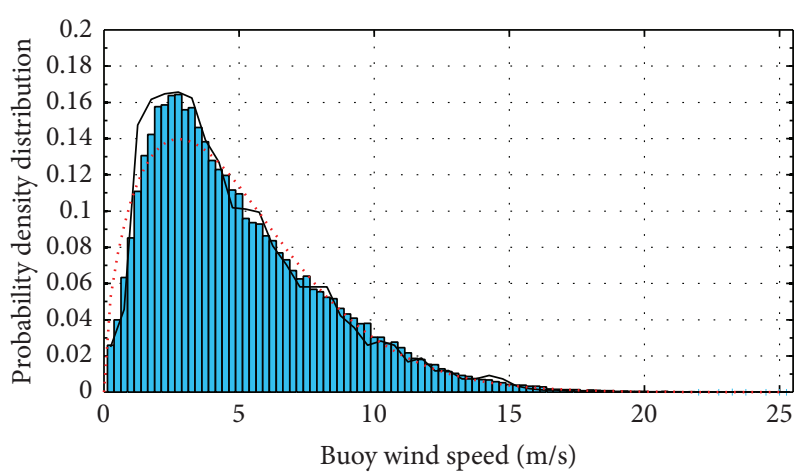

$60 \mathrm{~min}$ period vector average wind speed (2000-2014, 73830 samples)

- $60 \mathrm{~min}$ period vector average wind speed (06/2011-05/2012, 7872 samples)

Weibull fit to climatology

FIGURE 2: Histogram of the wind speed climatology computed using in situ hourly observations acquired by the "ODAS Italia 1" buoy in the period January 2000-March 2014. Superimposed are the Weibull fit (dotted line) to the climatology and the histogram (solid line) of the in situ wind speed observations used in the study.

Each data block consists of 4.5 seconds long time series of ambient noise sampled at $100 \mathrm{kHz}$. PAL subsampled each record eight times in order to create sequences of 1024 points corresponding to $10.24 \mathrm{~ms}$ that are Fast Fourier transformed (FFT) to generate 512-point spectra compressed to 64 frequency bins with a resolution of $200 \mathrm{~Hz}$ from 100 to $3000 \mathrm{~Hz}$ and of $1 \mathrm{kHz}$ from 3 to $50 \mathrm{kHz}$.

All spectra are processed in real time through a classification algorithm based on the detection of different sound sources by means of their acoustic signature and are recorded in the internal memory of the system.

PAL decides the time delay for acquiring the next data block according to the type of sources detected.

2.2. W1M3A Observing System. The concept of M3A [27] dates back to 2003 in the framework of the "Mediterranean Forecasting System-Pilot Project" (MFSPP) [28] where a network of permanent moored observatories was designed with the aim of continuously monitoring physical and meteorological parameters in the open Mediterranean Sea.

In addition to the W1M3A deployed in the Ligurian Sea, the network consists of the "Eastern 1 M3A" (E1M3A) observatory moored in the Cretan Sea and the "Eastern 2 M3A" (E2M3A) platform positioned in the southern Adriatic Sea.

The W1M3A observatory is positioned on a deep sea bed of $1200 \mathrm{~m}$ at about $80 \mathrm{~km}$ far from the Ligurian coast. It is exposed to high winds and waves from the Gulf of Lion as well as from Italian seas; thus it might be useful for detecting early signs of incoming severe weather and for sending prompt information and warning.

The observatory consists of two separate moorings: the "ODAS Italia 1" spar buoy hosting meteorological and oceanographic instruments and a subsurface mooring equipped with CTDs and ADCP deployed nearby the main one occasionally.
The "ODAS Italia 1" buoy is the only example of spar platform in the Mediterranean Sea and one of the few in the world and constitutes of a steel pole of about $50 \mathrm{~m}$ of length of which $36 \mathrm{~m}$ corresponds to the submersed part. It is subdivided into four sections: the upper three are water-tight whereas the last one is filled with water. The centrepiece of the upper three segments is characterized by a thicker portion in order to enhance platform stability and buoyancy and the last portion has a stabilizing disk which dampens buoy vertical motion.

Thus, the buoy has a negligible sensitivity to sea heave, which makes it a very suitable platform to acquire meteorological data over the ocean, especially in the case of rough seas and during storms, weather conditions that prohibit collecting meaningful in situ experimental data [29].

At about $10 \mathrm{~m}$ above sea surface there is a small laboratory containing all electronics needed to power the instrumentation and acquire and transmit data and on its very top a trellis hosts the meteorological sensors, the beacon, and the transmitting antenna. The external walls of the laboratory are covered by solar panels and a wind generator is installed on a trellis in order to guarantee power supply to the overall system in all seasons and weather conditions.

The buoy has the capability to measure in a continuous and affordable way a complete set of meteorological parameters as well as physical and biogeochemical sea-water properties. It is equipped with a barometer, a $2 \mathrm{D}$ and a $3 \mathrm{D}$ anemometer, a thermohygrometer, a pyranometer, and a pyrgeometer. Moreover a compact weather station provides additional measurements of wind speed and direction, air temperature, relative humidity, atmospheric pressure, and rainfall rate.

The oceanographic payload is formed by six probes to collect temperature and salinity from the surface down to $28 \mathrm{~m}$ depth and by a multiparametric probe installed at $36 \mathrm{~m}$ depth that allows measurements of dissolved oxygen, chlorophyll-a, and turbidity.

At $10 \mathrm{~m}$ depth, the buoy has an array of upward looking echo-sounders that permits the estimation of sea wave statistics.

All data are collected by a control and acquisition system based on an embedded intelligent controller. The system is able to acquire data continuously and it is developed to incorporate stand-alone sensors, for example, the PAL. All acquired data are preprocessed on board and then transmitted on shore. The transmission system provides necessary tools for exchanging commands, information, and data with the remote system ashore by means of an IRIDIUM satellite phone link.

2.3. Weather Radar. The weather radar on Monte Settepani is located at about 1400 meters above sea level $\left(44.247^{\circ} \mathrm{N}\right.$; $8.199^{\circ} \mathrm{E}$ ) and near the coastline, at $87 \mathrm{~km}$ range from the buoy location. It employs a $136 \mathrm{Km}$ range operational scan and has Doppler and dual-polarization capabilities, achieved through alternate transmission of horizontally and vertically polarized signals.

A fuzzy logic approach based on Doppler and dual-polarization measurements [30] is used to identify the nonmeteorological echoes (clutter) on the radar volume data. The reflectivity observations are subsequently corrected for path 
attenuation using a range profiling technique [31] and are characterized by a spatial resolution of $800 \mathrm{~m}$ and a temporal frequency of five minutes. During winter a correction for the vertical profile of reflectivity is applied [32] in order to compensate for the radar sampling at high altitudes in the ice or mixed-phase portion of the cloud.

Finally, in order to estimate the rainfall rate, an empirical relation is applied on the corrected reflectivity field [33]:

$$
Z=300 R^{1.5}
$$

where $Z$ is the reflectivity expressed in linear units $\left(\mathrm{mm}^{6} \mathrm{~m}^{-3}\right)$ and $R$ is the rainfall rate in $\mathrm{mm} / \mathrm{h}$.

\section{Data and Methods}

3.1. Meteorological Observations. On the upper part of the trellis of the "ODAS Italia 1" buoy, at about $10 \mathrm{~m}$ above sea level, a WindSonic 2D sonic anemometer and a Weather Transmitter WXT510 were providing data for the duration of the experiment.

The WindSonic 2D anemometer measures wind speed and direction by means of two pairs of transducers oriented in an orthogonal way that, in order to minimize the effect of flow distortion and shadowing, bounce the signal from a hood [34].

The Weather Transmitter WXT510 is a small and lightweight transmitter of six meteorological parameters in one compact package. The instrument uses the Vaisala RAINCAP sensor 2-technology [35] based on the acoustic detection of each rain drop as it impacts the sensor cover and provides a signal proportional to the volume of the drops; thus the voltage signal provided by the impact of each drop is directly converted to accumulated rainfall. Noise filtering techniques are applied to filter out signals originating from other sources than raindrops.

During LiSAE a total of 5,658,358 joint observations for both wind speed and rainfall were acquired. Figure 3 shows all available hourly accumulated rainfall and average wind speed with the highlighting of those related to the two major coastal floods inducing storm events that occurred in the fall of 2011.

The rainfall measurements provided by the WXT510 were compared to hourly cumulative rainfall observations extracted from the radar image in the closest grid point to the buoy position.

The spatial resolution of the radar data was $800 \mathrm{~m}$ for each sample, while the on-board buoy measurements represent a single point: direct comparison of the two data sets evidenced a correlation coefficient of 0.68 , an absolute mean bias of $0.07 \mathrm{~mm} / \mathrm{h}$, and a root mean square error of $0.82 \mathrm{~mm} / \mathrm{h}$.

A very good agreement in detecting rainfall events and high performances were obtained considering the contingency table computed using the temporal matchup of all available hourly data provided by the WXT510 and the radar.

Table 1 shows the results of the contingency table for two different thresholds: $0.1 \mathrm{~mm} / \mathrm{h}$ and $1 \mathrm{~mm} / \mathrm{h}$. The lower threshold $(0.1 \mathrm{~mm} / \mathrm{h})$ corresponds to the sensitivity of the rain gauge whereas the highest threshold $(1 \mathrm{~mm} / \mathrm{h})$ is used

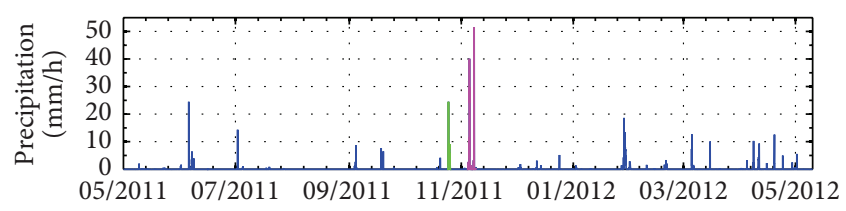

(a)

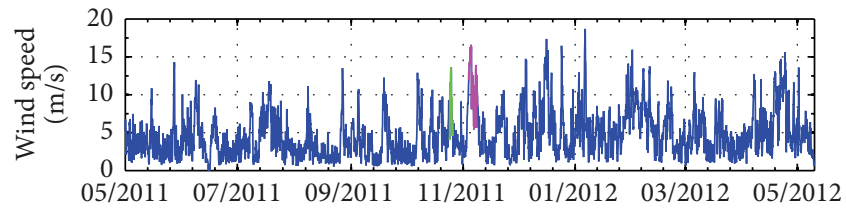

(b)

Figure 3: Times series of (a) hourly cumulative rainfall and (b) hourly averaged wind speed observations acquired by the rain gauge and the sonic anemometer during the experiment. Data corresponding to the major events on the 25th of October and 5th-8th of November 2011 are highlighted.

TABLE 1: Contingency table for the thresholds of (a) $0.1 \mathrm{~mm} / \mathrm{h}$ and (b) $1 \mathrm{~mm} / \mathrm{h}$. $R_{\text {buoy }}$ and $R_{\text {radar }}$ are the hourly cumulative rainfall measured by the rain gauge installed on the "ODAS Italia 1" buoy and estimated by radar, respectively.

(a)

\begin{tabular}{|c|c|c|}
\hline & \multicolumn{2}{|c|}{ Radar } \\
\hline $\begin{array}{l}\text { Rain at buoy } \\
\text { location } \\
\text { (254 samples) }\end{array}$ & $\begin{array}{c}\text { Correct } \\
\left(R_{\text {buoy }}>0.1 \mathrm{~mm} / \mathrm{h} \text { and }\right. \\
\left.R_{\text {radar }}>0 \mathrm{~mm} / \mathrm{h}\right) \\
188(72.83 \%)\end{array}$ & $\begin{array}{c}\text { Miss } \\
\left(R_{\text {buoy }}>0.1 \mathrm{~mm} / \mathrm{h} \text { and }\right. \\
\left.R_{\text {radar }}=0 \mathrm{~mm} / \mathrm{h}\right) \\
69(27.16 \%)\end{array}$ \\
\hline $\begin{array}{l}\text { No rain at buoy } \\
\text { location } \\
\text { (6584 samples) }\end{array}$ & $\begin{array}{c}\text { False alarm } \\
\left(R_{\text {buoy }}=0 \mathrm{~mm} / \mathrm{h} \text { and }\right. \\
\left.R_{\text {radar }}>0 \mathrm{~mm} / \mathrm{h}\right) \\
61(0.92 \%)\end{array}$ & $\begin{array}{c}\text { Correct } \\
\left(R_{\text {buoy }}=0 \mathrm{~mm} / \mathrm{h} \text { and }\right. \\
\left.R_{\text {radar }}=0 \mathrm{~mm} / \mathrm{h}\right) \\
6523(99.07 \%)\end{array}$ \\
\hline
\end{tabular}

(b)

\begin{tabular}{|c|c|c|}
\hline & \multicolumn{2}{|c|}{ Radar } \\
\hline $\begin{array}{l}\text { Rain at buoy } \\
\text { location } \\
\text { (117 samples) }\end{array}$ & $\begin{array}{c}\text { Correct } \\
\left(R_{\text {buoy }}>1 \mathrm{~mm} / \mathrm{h} \text { and }\right. \\
\left.R_{\text {radar }}>0 \mathrm{~mm} / \mathrm{h}\right) \\
99(84.61 \%)\end{array}$ & $\begin{array}{c}\text { Miss } \\
\text { (buoy }>1 \mathrm{~mm} / \mathrm{h} \text { and } \\
\left.R_{\text {radar }}=0 \mathrm{~mm} / \mathrm{h}\right) \\
18(15.33 \%)\end{array}$ \\
\hline $\begin{array}{l}\text { No rain at buoy } \\
\text { location } \\
\text { ( } 6721 \text { samples) }\end{array}$ & $\begin{array}{c}\text { False alarm } \\
\left(R_{\text {buoy }} \leq 1 \mathrm{~mm} / \mathrm{h} \text { and }\right. \\
\left.R_{\text {radar }}>0 \mathrm{~mm} / \mathrm{h}\right) \\
147(2.18 \%)\end{array}$ & $\begin{array}{c}\text { Correct } \\
\left(R_{\text {buoy }} \leq 1 \mathrm{~mm} / \mathrm{h} \text { and }\right. \\
\left.R_{\text {radar }}=0 \mathrm{~mm} / \mathrm{h}\right) \\
6574(97.81 \%)\end{array}$ \\
\hline
\end{tabular}

as the criterion to ensure that there is rain around the buoy position.

In situ buoy rainfall observations and radar estimates agree with more than $70 \%$ in case of rain greater than $0.1 \mathrm{~mm} /$ $\mathrm{h}$ and with more than $80 \%$ for rain greater than $1 \mathrm{~mm} / \mathrm{h}$ and, generally, in situ measurements reveal more rainfall episodes than radar estimates. On the contrary, for very few occasions, radar detected rain when no rain is measured by the rain gauge located on the buoy. 
3.2. Underwater Acoustic Data. The acoustic data set acquired by PAL during LiSAE experiment consisted in 55063 spectra with an average of 167 spectra per day (about 7 spectra per hour).

Each spectrum as soon as acquired was internally processed in order to be associated with different sources (drizzle, rain, wind, passing ship, and transient sound).

The classification algorithm is based on the statement that each sound that constitutes the ambient noise can be detected by means of spectral analysis: sound pressure levels at different frequencies; their slopes and also their duration allow distinguishing their sources. The classification of the sources is used by PAL to define its sampling strategy to optimize battery endurance and storage capability. If transient sound is detected, the acoustic device will take the next data blocks after 9 minutes; otherwise if it recognizes rain or convective rain events, it will acquire new data blocks every 2 minutes whereas if it distinguishes drizzle phenomena, it will collect data blocks every 4 minutes.

The identification of the different acoustic sources is based on a multivariate analysis considering combinations of acoustic spectral levels at peculiar frequencies and spectral slopes calculated as the least-square fit to sound pressure levels over selected frequency bands.

Furthermore, uniform sounds can be ascribed to the presence of wind constantly blowing, whereas burst of low frequency sounds can be associated with passing ship and noise produced by rain which is characterized by peaks in the spectra that differ according to precipitation type (e.g., convective rainfall versus widespread stratiform precipitation).

Figure 4 shows, as an example, one of the scatter tests used for the classification based on the combination between sound pressure levels at $20 \mathrm{kHz}$ and $8 \mathrm{kHz}$ for the period June-September 2011. The categories of sound sources considered in the multivariate analysis (wind speed, rainfall, drizzle, and passing ship) are detected in their generic position on the plot.

On hourly basis the acoustic device transmitted to the acquisition system on board the buoy a statistical report consisting of information about the number of samples taken during the previous hour, the percentage of time in which wind, rain, and noise phenomena were identified, the estimated average wind speed, and rainfall quantity.

For the duration of the experiment, the internal clock of the PAL was synchronized to the GPS time acquired by the buoy; thus sound pressure levels, in situ wind speed, and rainfall observations can be compared with a maximum delay of 5 seconds that is the sampling interval of the meteorological measurements collected by the buoy.

Figure 5 shows a subset of PAL spectra for one-month period (October 15 to November 15, 2011). Rainfall and wind speed measurements collected simultaneously by the surface buoy meteorological sensors are superimposed to the spectra. It is worth noting that in the frequency band up to $20 \mathrm{kHz}$ the sound intensity variations over time fit well to the wind speed time series and those high sound intensities in the frequency band precisely correspond to the two major storms that give rise to coastal floods.

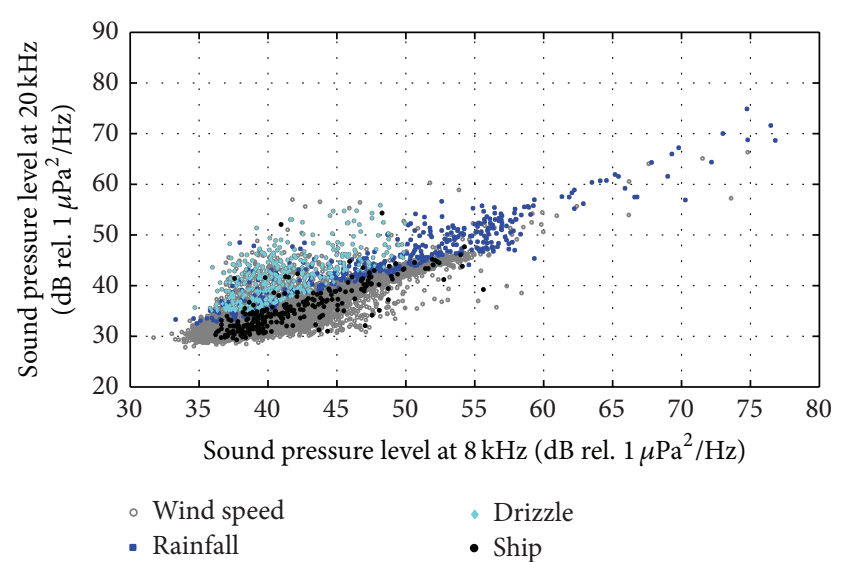

FIGURE 4: Scatter test of the $20 \mathrm{kHz}$ versus $8 \mathrm{kHz}$ sound pressure levels acquired from June to September 2011. Different symbols refer to different types of phenomena or events as detected and estimated using Passive Aquatic Listener.

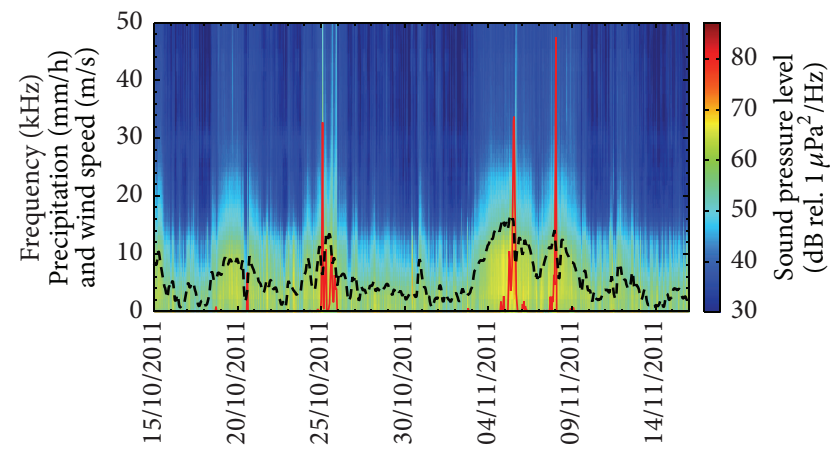

FIgURE 5: Sound pressure level spectra acquired by PAL between October 15 and November 15, 2011 and, superimposed, rainfall rates (solid line) and wind speed measurements (dashed line) collected by the rain gauge and the sonic anemometer on board the buoy, respectively. Three major stormy events passed over the buoy position on October 25, November 5, and November 7-8, 2011.

3.3. Rainfall Detection and Quantification. The sound generated by the splashing of raindrops at sea surface is derived not only from their impact but also from the subsequent formation of underwater bubbles.

The predominant sound of these two effects is depending on raindrops size that is inversely proportional to their resonance frequency. Bubbles with larger diameter are characterized by powerful sounds at lower frequencies and vice versa bubbles with smaller size produced sound at higher frequency.

As the drop size changes, the shape of the splash changes and subsequently the sound is modified. Pumphrey et al. [36] pointed out that although the sound produced by the splash of the drops is very quiet its geometry is such that a bubble is generated by each splash in very predictable manner.

PAL listens to the sound produced by the rain drops on the surface of the ocean and its classification algorithm categorizes rain type into drizzle if it associates the sound to 


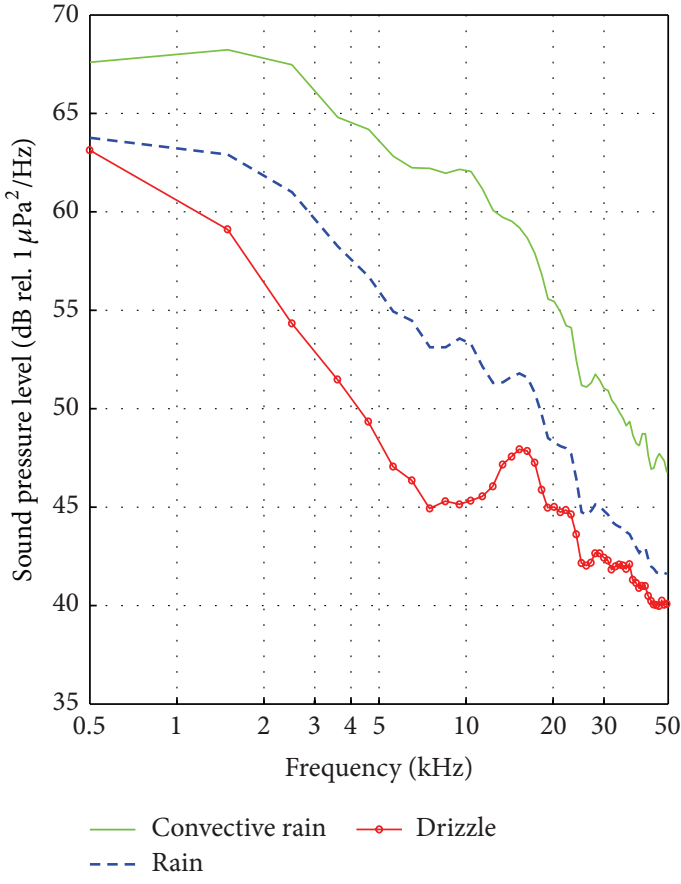

(a)

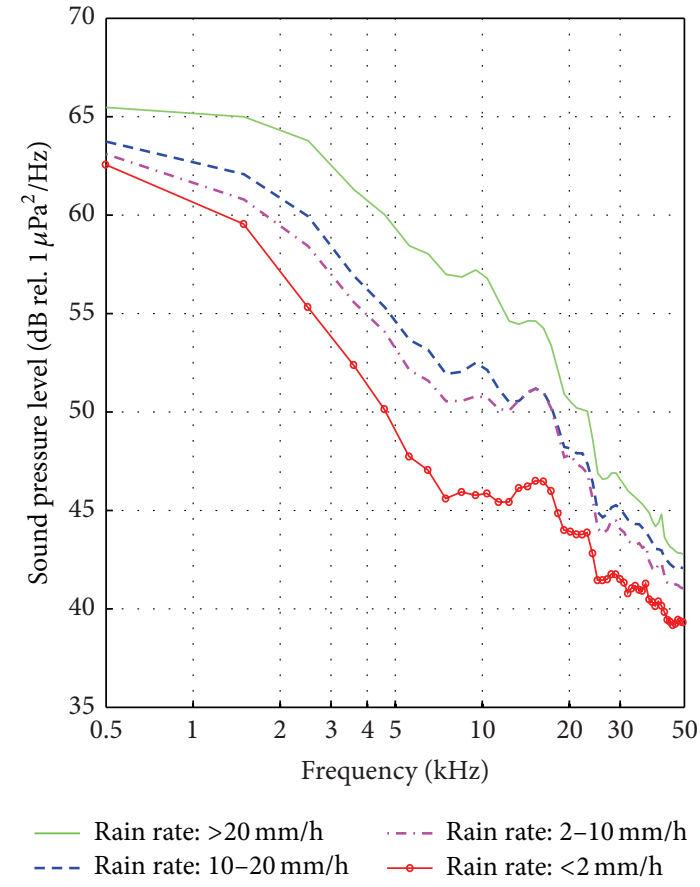

(b)

Figure 6: (a) Average sound spectra for different types of precipitation: convective rain, rain, and drizzle as classified by PAL; (b) average sound spectra subdivided into rainfall rate categories: $0-2,2-10$, and $10-20$, over $20 \mathrm{~mm} / \mathrm{h}$, respectively, as measured by the rain gauge on board the buoy.

raindrops with a diameter of less than $1 \mathrm{~mm}$, moderate stratiform rain if it identifies the sound as produced by drops of diameter comprised between $2 \mathrm{~mm}$ and $3 \mathrm{~mm}$, and heavy convective rain if it estimates that sound is generated by drops exceeding $3 \mathrm{~mm}$.

The classification algorithm analyzes spectral features of the acquired data blocks in order to identify a peak in the $15 \mathrm{kHz}-22 \mathrm{kHz}$ frequency range corresponding to the resonance frequency of smaller bubbles, intense sound around $10 \mathrm{kHz}$ corresponding to the sound produced by the underwater entrapment of bubbles with different size during the splash, and peaks in the frequency band $1 \mathrm{kHz}-2 \mathrm{kHz}$ for very large raindrops whose splat is very loud [37].

The sound associated with rain and heavy rain is unambiguous with respect to the sound produced by wind; on the contrary, drizzle signal can be suppressed by wind and both show similar features at $15 \mathrm{kHz}$ [38] giving rise to errors in the classification especially when the rainfall rate decreases and the wind speed increases.

This is the main source of error in the rainfall detection and quantification algorithms that were used in previous experiments $[19,20]$.

In order to evaluate classification and quantification performance of the algorithms for rain estimates in the Ligurian Sea, all sound pressure levels collected by PAL during the LiSAE experiment were examined by means of spectral analysis.
To assess the classification algorithm, average spectra of all data blocks identified by PAL as drizzle, rain, and convective rain were compared to the average spectra of rainfall observations provided by the buoy subdivided into 4 classes: $0-2 \mathrm{~mm} / \mathrm{h}, 2-10 \mathrm{~mm} / \mathrm{h}, 10-20 \mathrm{~mm} / \mathrm{h}$, and greater than $20 \mathrm{~mm} / \mathrm{h}$ (Figure 6).

The comparison between the mean spectra corresponding to the events flagged by PAL as drizzle and the events in which in situ observations showed a rainfall rate lower than $2 \mathrm{~mm} / \mathrm{s}$ exhibits the same characteristic with a peak around $15 \mathrm{kHz}$ denoting that spectral features used to detect drizzle are appropriate. The average spectra corresponding to data flagged by PAL as rain show decreasing trends at about $1,5 \mathrm{kHz}$ similar to the average spectra calculated for all rain episodes with rain rate comprised between 2 and $20 \mathrm{~mm} / \mathrm{h}$. Episodes classified by PAL as convective rain show greater values in the band between 2 and $10 \mathrm{kHz}$ and the same flatter spectra of the average curves corresponding to events with rainfall rate over $20 \mathrm{~mm} / \mathrm{h}$, confirming also in case of rain and convective rain a good automatic classification. Moreover, the characteristic peak of drizzle becomes undetectable for rain over $20 \mathrm{~mm} / \mathrm{h}$, but it is still noted for rainfall rates between $2 \mathrm{~mm} / \mathrm{h}$ and $10 \mathrm{~mm} / \mathrm{h}$.

In the frequency band $2-8 \mathrm{kHz}$, the slope of the sound pressure level spectra is flatter for the high rain category. This is due to the presence of large drops in heavier rainfall rates which produce sound in this frequency band. In other words, 
the steeper slope of the spectrum for drizzle comes from the background sound spectrum (i.e., the wind) and not from the rainfall itself.

No difference is noted in the spectral levels in the range of $2-10 \mathrm{~mm} / \mathrm{h}$ and $10-20 \mathrm{~mm} / \mathrm{h}$ in the frequency band from 11 to $18 \mathrm{kHz}$.

Since the presence of wind could mask rainfall events, an analysis based on the subdivision of spectra for rainfall rate classes sorted by wind speed has been carried out using the data acquired by the buoy.

The analysis was made for rainfall rates lower than $2 \mathrm{~mm} /$ $\mathrm{h}$, between $2 \mathrm{~mm} / \mathrm{h}$ and $10 \mathrm{~mm} / \mathrm{h}$, and between $10 \mathrm{~mm} / \mathrm{h}$ and $20 \mathrm{~mm} / \mathrm{h}$, for values greater than $20 \mathrm{~mm} / \mathrm{h}$, in correspondence with wind speed lower than $4 \mathrm{~m} / \mathrm{s}$, between $4 \mathrm{~m} / \mathrm{s}$ and $6 \mathrm{~m} / \mathrm{s}$, and between $6 \mathrm{~m} / \mathrm{s}$ and $10 \mathrm{~m} / \mathrm{s}$, and for quantities greater than $10 \mathrm{~m} / \mathrm{s}$ when a sufficient number of samples were available, otherwise for combined classes of cited wind speed (Figure 7).

For wind speeds greater than $10 \mathrm{~m} / \mathrm{s}$ the spectra show the same dynamic range at all rainfall rates with a decreasing signal up to $10 \mathrm{kHz}$ where a small peak is observed and again a decrease that, for frequency greater than $25 \mathrm{kHz}$, shows sound pressure levels lower than those in the other classes of rain and heavy rain. Drizzle signal is clearly visible and it is associated with low rainfall rate and gentle breeze. The specific peak of drizzle is progressively masked by the increasing of wind speed: for rainfall rate lower than $2 \mathrm{~mm} / \mathrm{h}$ even a wind speed greater than $4 \mathrm{~m} / \mathrm{s}$ is sufficient to make this peak less evident, whilst for intermediate rainfall rates $(2-10 \mathrm{~mm} / \mathrm{h})$ the peak is still present for wind speeds up to $6 \mathrm{~m} / \mathrm{s}$.

Results confirmed that wind speed does not influence significantly the shape of the rainfall spectra in the frequency band up to $10 \mathrm{kHz}$ suggesting that combinations of acoustic spectral levels up to $10 \mathrm{kHz}$ as discriminator for rain detection are appropriate. Specifically, spectra levels at $5 \mathrm{kHz}$ show the highest variation with respect to precipitation amount and monotonically increase as rainfall increases, confirming that the use of the sound pressure levels at $5 \mathrm{kHz}$ is suitable to be used for the quantification algorithm. Over $25 \mathrm{kHz}$ frequency sound pressure levels tend to decrease as wind speed reinforces.

The availability of simultaneous acoustic rainfall measurements, in situ observations, and radar estimates made possible, for the first time, the evaluation of the classification algorithm in the Ligurian basin on the basis of the contingency table statistics (Table 2). One year of hourly cumulated rainfall data collected by the buoy from June 2011 to May 2012 was considered as ground truth and the same thresholds used for the aforementioned comparison with radar estimates (namely, $0.1 \mathrm{~mm} / \mathrm{h}$ and $1 \mathrm{~mm} / \mathrm{h}$ ) were chosen.

Results show a high rate of correct detection for both thresholds with an increase in the percentage corresponding to the detection of rain when the greater threshold is used. Miss values decrease as the threshold increases due to the sampling scheme of PAL. Indeed, storms associated with very low quantity of rainfall or intermittent duration might be not sampled appropriately by PAL.

The probability of rain detection has always a high score and the percentage of false alarms increases for the greater
TABLE 2: Contingency table for the thresholds of (a) $0.1 \mathrm{~mm} / \mathrm{h}$ and (b) $1 \mathrm{~mm} / \mathrm{h}$. $R_{\text {buoy }}$ and $R_{\mathrm{PAL}}$ are the hourly cumulative rainfall measured by the rain gauge installed on the "ODAS Italia 1" buoy and estimated by PAL, respectively.

(a)

\begin{tabular}{lcc}
\hline \multicolumn{2}{c}{ PAL } \\
\hline Rain at buoy & Correct & Miss \\
location & $\left(R_{\text {buoy }}>0.1 \mathrm{~mm} / \mathrm{h}\right.$ and & $\left(R_{\text {buoy }}>0.1 \mathrm{~mm} / \mathrm{h}\right.$ and \\
$(286$ samples $)$ & $\left.R_{\text {PAL }}>0 \mathrm{~mm} / \mathrm{h}\right)$ & $\left.R_{\mathrm{PAL}}=0 \mathrm{~mm} / \mathrm{h}\right)$ \\
& $167(58.39 \%)$ & $119(41.61 \%)$ \\
\hline \multirow{2}{*}{ No rain at buoy } & False alarm & Correct \\
location & $\left(R_{\text {buoy }}=0 \mathrm{~mm} / \mathrm{h}\right.$ and & $\left(R_{\text {buoy }}=0 \mathrm{~mm} / \mathrm{h}\right.$ and \\
(7569 samples $)$ & $\left.R_{\mathrm{PAL}}>0 \mathrm{~mm} / \mathrm{h}\right)$ & $\left.R_{\mathrm{PAL}}=0 \mathrm{~mm} / \mathrm{h}\right)$ \\
& $40(0.52 \%)$ & $7529(99.48 \%)$ \\
\hline
\end{tabular}

(b)

\begin{tabular}{lcc}
\hline & \multicolumn{2}{c}{ PAL } \\
\hline Rain at buoy & Correct & Miss \\
location & $\left(R_{\text {buoy }}>1 \mathrm{~mm} / \mathrm{h} \&\right.$ & $\left(R_{\text {buoy }}>1 \mathrm{~mm} / \mathrm{h} \&\right.$ \\
(137 samples) & $\left.R_{\mathrm{PAL}}>0 \mathrm{~mm} / \mathrm{h}\right)$ & $\left.R_{\mathrm{PAL}}=0 \mathrm{~mm} / \mathrm{h}\right)$ \\
& $115(83.94 \%)$ & $22(16.06 \%)$ \\
\hline \multirow{2}{*}{ No rain at buoy } & False alarm & Correct \\
location & $\left(R_{\text {buoy }} \leq 1 \mathrm{~mm} / \mathrm{h}\right.$ and & $\left(R_{\text {buoy }} \leq 1 \mathrm{~mm} / \mathrm{h}\right.$ and \\
(7718 samples) & $\left.R_{\mathrm{PAL}}>0 \mathrm{~mm} / \mathrm{h}\right)$ & $\left.R_{\mathrm{PAL}}=0 \mathrm{~mm} / \mathrm{h}\right)$ \\
& $92(1.19 \%)$ & $7626(98.81 \%)$ \\
\hline
\end{tabular}

threshold; consequently, the correct detection rate decreases when no rain condition exists for both buoy and PAL. This is consistent with PAL operating mode since, if PAL is active, it is able to distinguish also very low quantities of drops.

Comparing Table 2 with Table 1 it is worth noting the elevate percentage (greater than 97\%) of agreement between PAL, radar, and buoy sensor when it does not rain (false alarms lesser than 3\%) and the very similar figures obtained for all cases (correct and miss detection, false alarms) when the threshold of $1 \mathrm{~mm} / \mathrm{h}$ is considered. In case of rain and using the lower threshold $(0.1 \mathrm{~mm} / \mathrm{h})$, the comparison between on-board rain gauge and PAL estimates shows worst performance with respect to the comparison of buoy measurements with radar rainfall data although correct detection rate of rain events is still greater than the miss percentage.

The assessment of the classification algorithm that was originally developed and applied in different oceanic locations [39] demonstrates its applicability also in the Ligurian Sea and suggests that it is not associated with the peculiar open-ocean noise characteristic of a specific basin.

Once the sample acquired by PAL is flagged as rainfall and classified into drizzle, rain, or heavy rain, a quantification algorithm is applied in order to estimate rainfall rate. The algorithm is based on the following empirical relationship [38] that relates sound intensity $(I)$ to rainfall rate $(R)$ :

$$
R=10^{\left(\left(\mathrm{SPL}_{5}-\alpha\right) / \beta\right)},
$$

where $\mathrm{SPL}_{5}$ is the sound pressure level ( $\mathrm{dB}$ rel. $1 \mu \mathrm{Pa}^{2} \mathrm{~Hz}^{-1}$ ) at $5 \mathrm{kHz} \alpha$ and $\beta$ are the intercept and the slope of the linear regression for $\mathrm{SPL}_{5}$ and the logarithmic rainfall rate, respectively. 

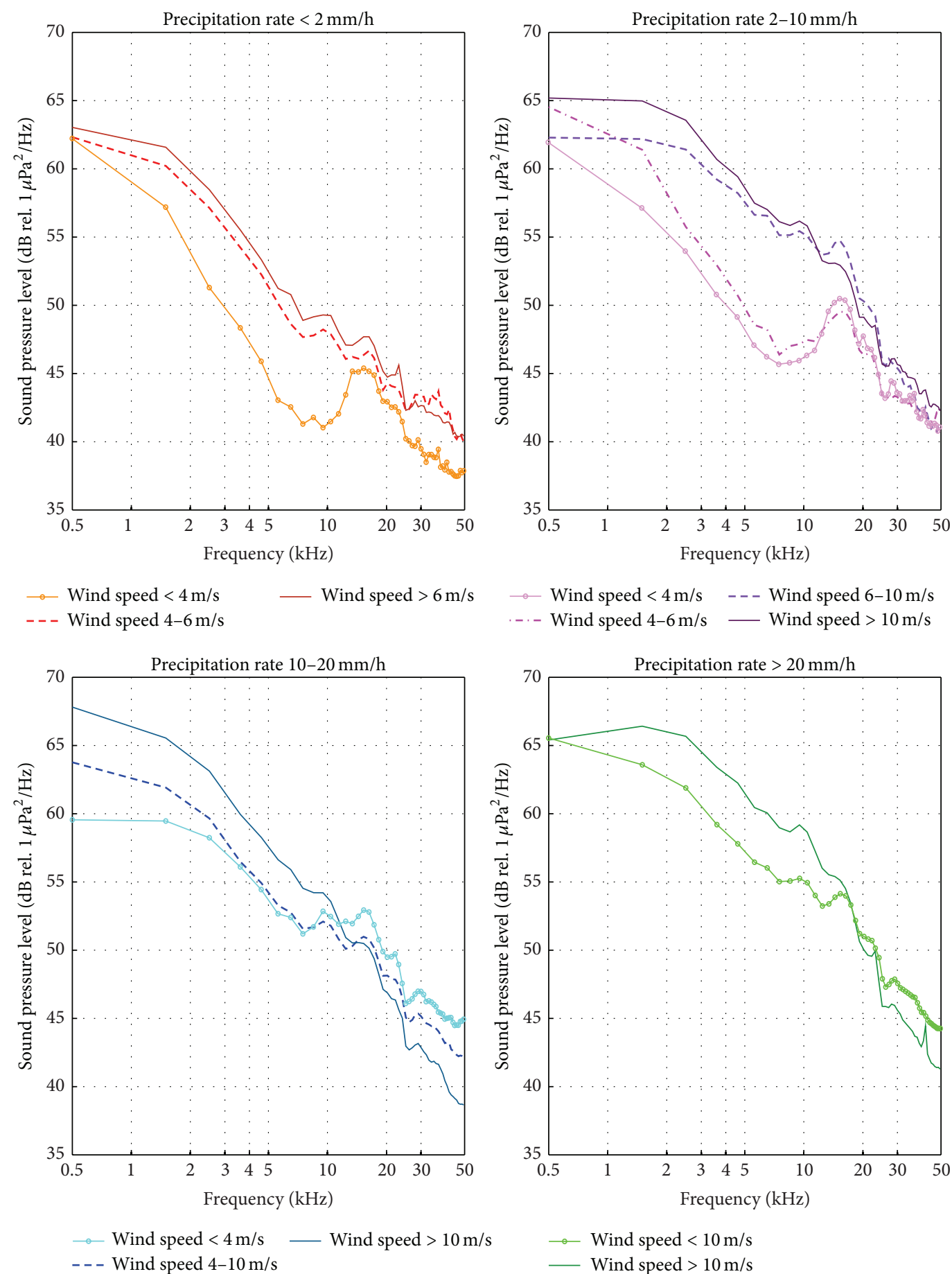

FIGURE 7: Average sound spectra at different rainfall rates $(0-2,2-10$, and $10-20$, over $20 \mathrm{~mm} / \mathrm{h})$ and wind speed categories as measured by instruments installed on board the buoy.

Several studies were performed to validate the rainfall quantification relationship in different environmental conditions and results showed a good agreement between PAL quantification against both in situ measurements and radar estimates [11, 19].

However, coefficients of (2) may vary from experiment to experiment.
In order to evaluate and enhance the rainfall algorithm in the Ligurian Sea, taking advantage for the first time of high resolution rainfall in situ data, an analysis was carried out considering all acquired $\mathrm{SPL}_{5}$ and corresponding rainfall measurements collected by the rain gauge installed on board the "ODAS Italia 1" buoy from June 2011 to May 2012. 


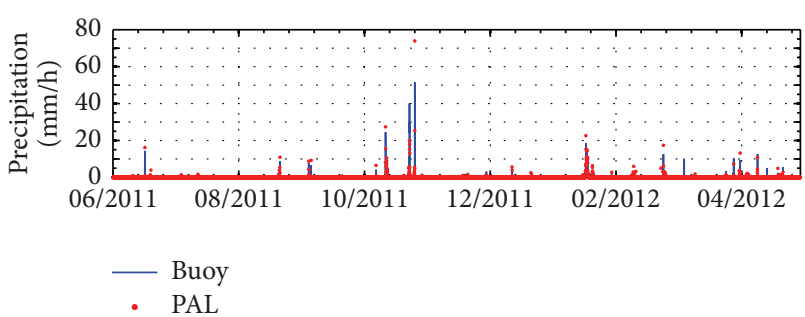

(a)

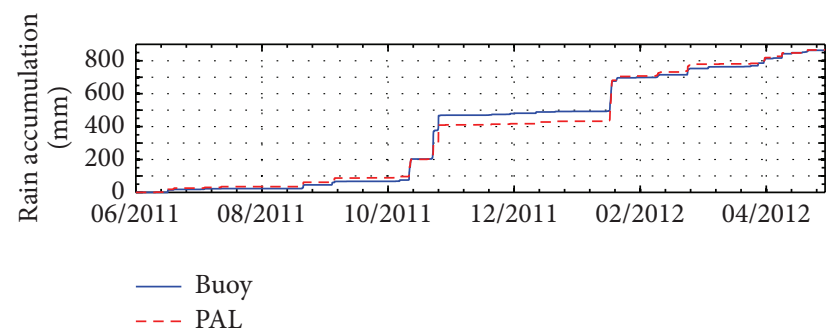

(b)

Figure 8: (a) Time series of rain rates and (b) rain accumulation throughout the whole experimental period acquired by the rain gauge on board the buoy and derived from the acoustic noise collected by the Passive Aquatic Listener.

The Ligurian basin generally shows very low rate of rainfall in summer associated with low wind speed and heavy storms in autumn characterized by strong winds. Using the method and the equation proposed by Ma and Nystuen [18] and by Anagnostou et al. [19], a systematic underestimation of rainfall during convective precipitation and an overestimation for drizzle were observed. In order to reduce these errors and improve the performance of the algorithm, a new formulation taking into account two rainfall types is proposed.

Two training sets of a random selection of pairs of rain amount and correspondent SPL5 for the two rainfall types (drizzle, rain, and heavy rain) were created including a number of events statistically sufficient to cover the expected range of variation for both phenomena. The rest of the pairs were used as a test set to validate the new formulation. Using the training sets two new couples of $\alpha$ and $\beta$ coefficients (intercept and slope of the linear regression, resp.) were computed for each rainfall type:

$$
\begin{gathered}
R=10^{\left(\left(\mathrm{SPL}_{5}-64.402\right) / 25\right)} \text { drizzle, } \\
R=10^{\left(\left(\mathrm{SPL}_{5}-65.645\right) / 17.86\right)} \text { rain and heavy rain. }
\end{gathered}
$$

The application of the new proposed algorithm to the time series of all available hourly rainfall acquisitions made by the buoy and the PAL shows a very good agreement for both individual storms and total accumulation with a correlation coefficient of 0.91 and a standard deviation of $0.54 \mathrm{~mm} / \mathrm{h}$ considering the difference between PAL estimates and in situ observations (Figure 8).

The flood that occurred on the 25th of October lasted 24 hours and the total amount of rainfall over the coastal area was quantified to be about $539 \mathrm{~mm}$ [40]. As storm approached

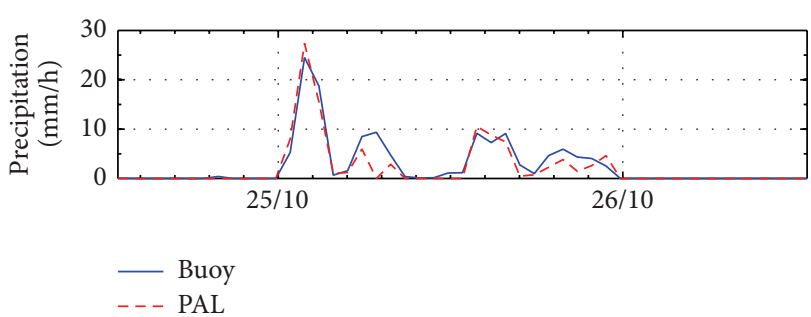

(a)

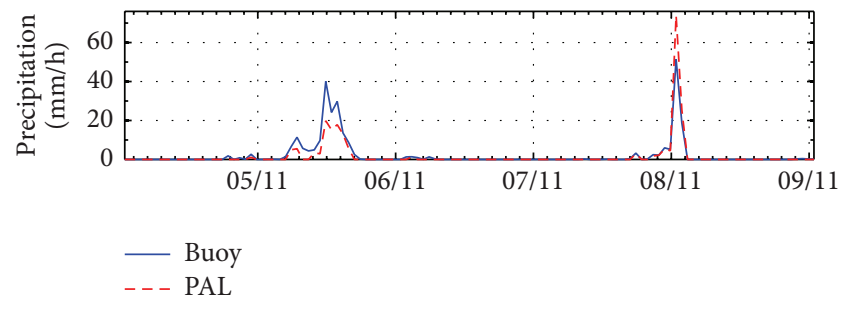

(b)

FIGURE 9: Buoy and PAL precipitation time series of the two floods. Rainfall rate comparison between buoy measurements and Passive Aquatic Listener estimates during two major flood events occurred on (a) October 25, 2011, in La Spezia and on (b) November 4-9, 2011, in Genoa.

the coast from the south it was well detected by both the buoy rain gauge and the PAL, with accumulations of $126.92 \mathrm{~mm}$ and $104.78 \mathrm{~mm}$, respectively, and a very good agreement in the temporal dynamic of the storm (Figure 9). Unfortunately, due to a failure on the Mount Settepani system, radar data were only available along the coastal area (from the Bric della Croce radar) and not offshore.

In the flood of the 4th and 5th of November, the maximum accumulation on land was about $365 \mathrm{~mm}$ [41]. The storm lasted five days and was well sampled by the radar. The buoy indicated a total amount of $264.95 \mathrm{~mm}$ and PAL of $206.47 \mathrm{~mm}$ showing again a very good agreement between the two systems (Figure 9).

Radar estimates show the same storm dynamics as provided by the rain gauge on buoy and the PAL, but a lesser amount of precipitation, which may be due to an underestimation of the polarimetric algorithm in the presence of relevant path attenuation. In addition, when heavy rain is falling at the radar location, a negative bias on the reflectivity measurements may be introduced by the radome wetting, which causes an excess attenuation of the transmitted and received signal [42]. On the other hand, when it is not raining at the radome, mainly over the sea, radar estimates show a very good agreement in dynamic and quantities with atmospheric and acoustic observations.

An example can be found by analyzing the intense phenomenon occurred in the last days of January 2012 when at sea the total amount of rain was $184.07 \mathrm{~mm}$ for rain gauge on the buoy, $249.10 \mathrm{~mm}$ for PAL, and $178.70 \mathrm{~mm}$ for radar and a nonparticular violent storm hit the coasts of Liguria. PAL estimates followed with a good approximation the dynamic of rainfall at sea for four days of perturbations characterized by an average wind speed of about $10 \mathrm{~m} / \mathrm{s}$ and radar observations 
TABLE 3: Synoptic events occurred during LiSAE experiment.

\begin{tabular}{|c|c|c|c|c|c|c|c|}
\hline Date & Duration (h) & $\begin{array}{c}\text { Average wind } \\
\text { speed }(\mathrm{m} / \mathrm{s})\end{array}$ & $\begin{array}{l}\text { Wind gust } \\
(\mathrm{m} / \mathrm{s})\end{array}$ & $\begin{array}{c}\text { Pal rainfall } \\
\text { amount }(\mathrm{mm})\end{array}$ & $\begin{array}{c}\text { Buoy rainfall } \\
\text { amount }(\mathrm{mm})\end{array}$ & $\begin{array}{l}\text { Rainfall on land } \\
\text { amount (mm) }\end{array}$ & Note \\
\hline Oct. 25,2011 & 22.25 & 10.1 & 20.6 & 104.78 & 126.92 & 539 & $\begin{array}{c}\text { Flood in the } \\
\text { Cinque Terre } \\
\text { villages }\end{array}$ \\
\hline Nov. 4-9, 2011 & 118.05 & 13.7 & 23.0 & 206.47 & 264.95 & 365 & Flood in Genoa \\
\hline Jan. 26-30, 2012 & 87.05 & 8.9 & 20.9 & 249.10 & 184.07 & 0 & $\begin{array}{c}\text { Rain at sea not } \\
\text { on land }\end{array}$ \\
\hline Jul. 27, 2011 & 1 & 3.2 & 3.9 & 0.75 & 0.11 & $\mathrm{n} / \mathrm{a}$ & Drizzle \\
\hline Set. 4, 2011 & 1.06 & 3.5 & 5.3 & 5.68 & 4.28 & $\mathrm{n} / \mathrm{a}$ & Drizzle \\
\hline Apr. 30, 2012 & 2 & 3.9 & 9.2 & 2.63 & 1.05 & $\mathrm{n} / \mathrm{a}$ & Drizzle \\
\hline
\end{tabular}

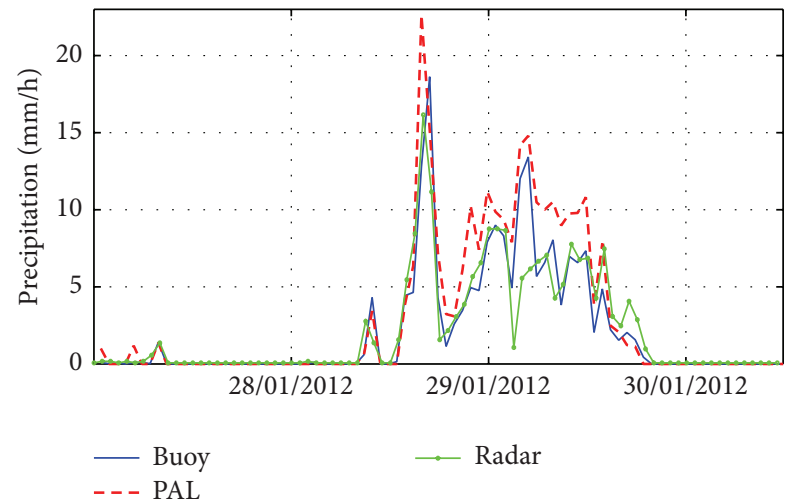

FIGURE 10: Buoy, PAL, and radar rainfall time series collected during the violent storm on late January 2012 over the buoy position.

agreed with buoy observations showing a very good correlation for all persistence of the storm except for few hours (Figure 10).

Discrepancies in the amount of rainfall estimated by PAL and measured by the rain gauge on the buoy can be ascribed to the different sampling strategies of the two systems: if rainfall occurred when PAL is in sleep mode the sensor will miss it whereas the buoy will be continuously monitoring and accumulating precipitation at 5-second interval.

Another issue regards the contamination of sound produced by wind on the sea surface that affects sound produced by rainfall especially in case of drizzle. Indeed, high wind speed values were recorded by the buoy not only during the two most intense events (the average was $10.03 \mathrm{~m} / \mathrm{s}$ and the gust $20.64 \mathrm{~m} / \mathrm{s}$ for the first flood and $13.76 \mathrm{~m} / \mathrm{s}$ and $23.03 \mathrm{~m} / \mathrm{s}$ for the second flood, resp.), but also during the last days of January 2012 (average of $8.9 \mathrm{~m} / \mathrm{s}$ and gust of $20.92 \mathrm{~m} / \mathrm{s}$ ) and during precipitation classified by PAL as rain collecting similar values. Analysing all drizzle periods the mean recorded wind speed was $4.4 \mathrm{~m} / \mathrm{s}$ with an average gust of $7 \mathrm{~m} / \mathrm{s}$, but in several episodes close in time to rain episodes wind speed had average of $7 \mathrm{~m} / \mathrm{s}$ and gust greater than $10 \mathrm{~m} / \mathrm{s}$. Table 3 summarises the most significant rain episodes.

On seasonal and annual basis, the accumulations estimated by buoy and PAL were very close to each other underlining that PAL is able to reproduce the climatologic behaviour of rainfall for the basin, with a slight tendency to overestimate the monthly cumulative rainfall quantity with respect to in situ observations.

3.4. Wind Detection and Quantification. Wind is always blowing over the sea apart from exceptional calm conditions lasting short time. The sound source for wind is breaking wind waves. However, if very light winds do not produce waves, wind is not acoustically detectable: this implies a physical lower limit for the acoustic wind speed algorithm at about $3 \mathrm{~m} / \mathrm{s}$ [43].

The classification of high wind is difficult because of the similitude of its sound with the one produced by ship passages, although the temporal sequence of noise generated by ships changes rapidly from one sample to the next when compared to wind speed dynamics.

The detection algorithm applied by PAL considers as wind all samples that are not recognized as rain and ship or mammals vocalization; that is, if no other sources are detected.

In order to assess the performance of the detection and quantification algorithms in the Ligurian Sea, wind speed estimates provided by PAL were compared to the high resolution in situ wind speed observations by means of spectral analysis.

To this aim all spectra collected by PAL during rain events detected by the rain gauge on board the buoy were discarded. It was also possible to discard PAL spectra corresponding to ship passages closer than $18 \mathrm{~km}$ from the buoy within 15 minutes using Automatic Identification System (AIS) data.

High resolution buoy wind data collected at 5-second intervals were smoothed by running average with a time window of 5 minutes and used to subdivide PAL sound pressure levels into wind classes according to Beaufort scale. PAL spectra and buoy observations were matched within 1 minute. The total number of available sound pressure level spectra decreased from 55063 to 50580 (Table 4).

No sound pressure level spectra were available for class F0, whereas for other classes up to class F6 a statistically significant number of samples were present.

Sound pressure level average spectra for each different Beaufort wind speed class are shown in Figure 11. The variability (standard deviation) for low wind speeds (F1-F3) is greater than the variability at greater wind speeds (F5-F7). 


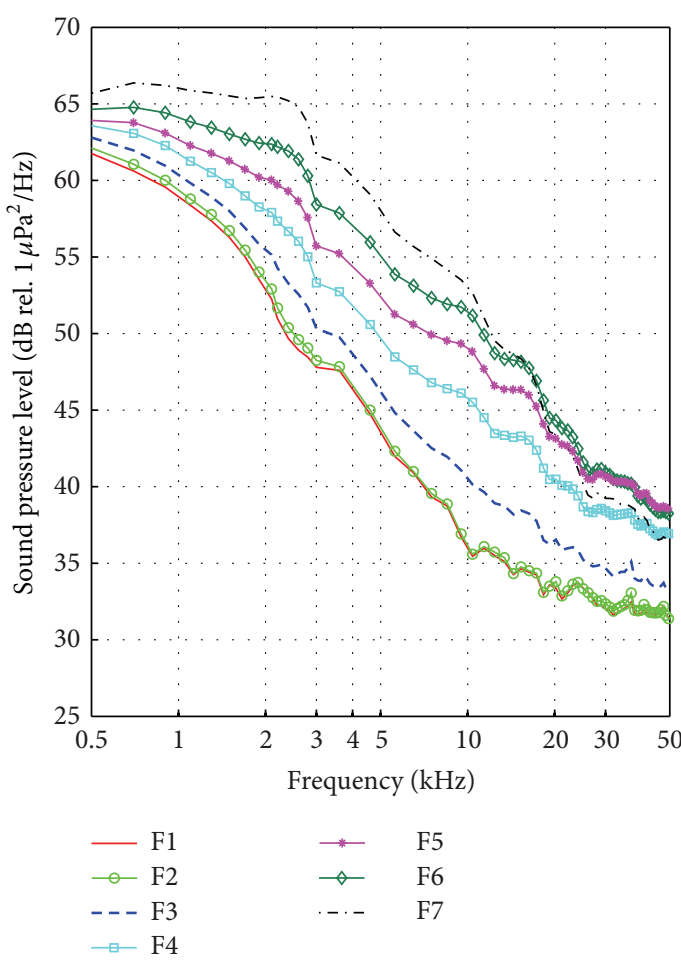

(a)

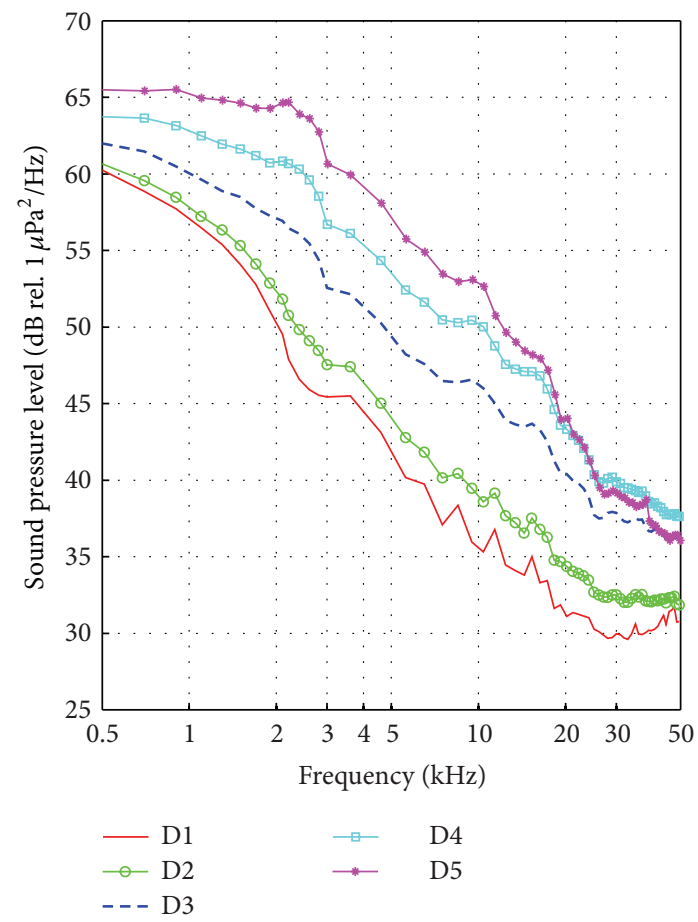

(b)

FIGURE 11: Sound pressure level average spectra collected by Passive Aquatic Listener divided into (a) Beaufort wind speed classes F1 to F7 as measured by the anemometer on board the buoy and (b) Douglas significant wave height classes D1 to D5 as estimated by the wave meter system of the buoy.

In case of light air or breeze (classes F1 and F2) the corresponding spectra show very similar features and they are almost undistinguishable. Spectral levels tend to increase monotonically with wind speed increasing except for the frequency band greater than $20 \mathrm{kHz}$ where sound intensities associated with very high wind speed classes F6 and F7 are quieter than intensities for class F5.

During very high wind conditions large waves arise and break injecting large number of bubbles into the ocean surface layer that subsequently absorbs sound produced by new breaking waves. Since PAL was deployed below the bubble layer, the recorded sound levels at higher frequencies were lower for very low wind speed conditions.

The dependence of sound intensities on wind waves is also apparent by considering the significant wave height parameter. During the 327 days of the experiment, significant wave height estimates were collected at 1-hour interval by the acoustic array of upward looking echo-sounders deployed at $10 \mathrm{~m}$ depth on the buoy. PAL spectra were extracted at the same time instant of the wave height measurements providing a total number of 4854 match-up pairs. Table 4 shows the number of pairs for each Douglas class of the sea state. The majority of the estimates were in classes 2, 3, and 4 with only about $11 \%$ for wave height higher than $2.50 \mathrm{~m}$.

Sound pressure level average spectra (Figure 11) increase almost monotonically from sea state D1 to sea state D4 throughout the frequency range $0-50 \mathrm{kHz}$.
Clusters of different wind speed classes can be identified in the acquired acoustic footprint in the bidimensional space of the sound pressure level at $8 \mathrm{kHz}$ and $20 \mathrm{kHz}$ (Figure 12). Distributions of wind speed tend to occupy the lower-left corner for low wind speeds (i.e., in calm conditions) and progressively move towards the upper-right side. This information was used to resolve ambiguity between sound produced by high wind and passing ship experienced in previous experiment.

The dominant feature of wind during LiSAE is clearly visible in the frequency band $2 \mathrm{kHz}-10 \mathrm{kHz}$, confirming the possibility of using the sound level at $8 \mathrm{kHz}\left(\mathrm{SPL}_{8}\right)$ for quantitatively estimating wind speed as proposed by Vagle et al. [43] with a validation range from $3.3 \mathrm{~m} / \mathrm{s}$ to $15 \mathrm{~m} / \mathrm{s}$ and subsequently by Anagnostou et al. [44] relative to the deployment of two PALs in the framework of the Poseidon II project.

Applying the algorithms proposed by Vagle at al. [43] to the data acquired by PAL during LiSAE (50580 pairs of 5minute average buoy wind speeds and corresponding $\mathrm{SPL}_{8}$ ) the resulting slope of the linear square fit indicated a tendency to overestimate low wind speeds and to underestimate high wind speeds. On the other hand, the results of the application of the equation introduced by Anagnostou et al. [44] were more correlated to wind gust, since they always overestimate wind speeds (Figure 13).

Results obtained through the application of Anagnostou et al. [44] curve evidenced a nonlinear trend and, in order to 
TABLE 4: Number of available sound pressure level spectra divided into (a) Beaufort wind speed and (b) Douglas seas state classes on the basis of 5-minute running average of wind speed and significant wave height measurements acquired by the anemometer and the wave meter system on board the buoy, respectively.

(a)

\begin{tabular}{lccc}
\hline Beaufort scale & $\begin{array}{c}\text { Wind speed } \\
(\mathrm{m} / \mathrm{s})\end{array}$ & $\begin{array}{c}\text { Number of } \\
\text { sound pressure } \\
\text { level spectra }\end{array}$ & Percentage \\
\hline F0-calm & $0-0.2$ & 0 & 0.00 \\
F1-light air & $0.3-1.5$ & 5690 & 11.25 \\
F2-light breeze & $1.6-3.3$ & 14616 & 28.90 \\
F3-gentle & $3.4-5.4$ & 12993 & 25.69 \\
breeze & & & \\
F4-moderate & $5.5-7.9$ & 9197 & 18.18 \\
breeze & $8.0-10.7$ & 5171 & 10.22 \\
F5-fresh breeze & $10.8-13.8$ & 2224 & 4.40 \\
F6-strong & $13.9-17.1$ & 689 & 1.36 \\
breeze & & 50580 & 100.00 \\
F7-near gale & & & \\
\hline Total & &
\end{tabular}

(b)

\begin{tabular}{lccc}
\hline Douglas scale & $\begin{array}{c}\text { Significant wave } \\
\text { height }(\mathrm{m})\end{array}$ & $\begin{array}{c}\text { Number of } \\
\text { sound pressure } \\
\text { level spectra }\end{array}$ & Percentage \\
\hline $\begin{array}{l}\text { D0-calm } \\
\text { (glassy) }\end{array}$ & - & 0 & 0.00 \\
$\begin{array}{l}\text { D1-calm } \\
\text { (rippled) }\end{array}$ & $0.00-0.10$ & 0 & 0.00 \\
D2-smooth & $0.10-0.50$ & 1714 & 35.31 \\
D3-slight & $0.50-1.25$ & 1599 & 32.94 \\
D4-moderate & $1.25-2.50$ & 1012 & 20.85 \\
D5-rough & $2.50-4.00$ & 416 & 8.57 \\
D6-very rough & $4.00-6.00$ & 113 & 2.33 \\
\hline Total & & 4854 & 100.00 \\
\hline
\end{tabular}

minimize the errors due to the overestimation of wind speed, a new relationship between high resolution wind speed $(U)$ at $10 \mathrm{~m}$ height measurements acquired contemporaneously and sound pressure level at $8 \mathrm{kHz}\left(\mathrm{SPL}_{8}\right)$ was introduced.

Two training sets of a random selection of pairs of rain amount and correspondent SPL8 for two wind categories (low wind speed and light breeze, moderate to strong breeze) were created including a number of events statistically sufficient to cover the expected range of variation for both classes of wind intensity. The rest of the pairs were used as a test set to validate the new formulation. Using the training sets two new fits (one linear for low wind speed, one quadratic for higher wind speeds) were computed:

$$
\begin{array}{r}
U=0.1458 \cdot \mathrm{SPL}_{8}-3.146 \quad 30<\mathrm{SPL}_{8}<38, \\
U=0.044642 \cdot \mathrm{SPL}_{8}{ }^{2}-3.2917 \cdot \mathrm{SPL}_{8}+63.016 \\
38 \leq \mathrm{SPL}_{8}<60 .
\end{array}
$$

The developed quantitative wind speed algorithm used two different equations in order to minimize the root mean square error: a linear fit for sound pressure levels between $30 \mathrm{~dB}$ and $38 \mathrm{~dB}$ corresponding to low wind speed and light breeze and a second-order equation for sound pressure levels equal to or greater than $38 \mathrm{~dB}$ corresponding to moderate, fresh, and strong breeze.

The new LiSAE algorithm showed best slope and intercept with respect to the applications of Vagle et al. [43] and Anagnostou et al. [44] equations even though the correlation coefficient between acoustic wind estimates provided by PAL in the experiment and surface buoy anemometer measurements is very high $(>0.91)$ for all three relationships.

Furthermore, the proposed LiSAE algorithm should be considered valid for $\mathrm{SPL}_{8}$ from 30 to $60 \mathrm{~dB}$ corresponding to wind speed between 2 and $25 \mathrm{~m} / \mathrm{s}$ and introduced the lowest limit with respect to previous formulations, although the onset of wind-induced wave breaking is usually set to $2.2 \mathrm{~m} / \mathrm{s}$, and this speed can be considered as the lowest detectable limit for any acoustic-based detection and quantification technique.

From operational point of view, that is, for basin-wide forecast model evaluation purposes, it might be more significant to provide a correct classification of wind speed class rather than wind speed estimates. In order to verify the skill of the three parameterizations to provide wind speed classification, a normalized decision matrix was computed for each wind speed class (Figure 14).

Results show that the greatest percentage for the correct class is obtained by the LiSAE relationship except for Beaufort class $\mathrm{F} 1$, for which the potential of revealing and estimating wind field at the surface is limited since there are no windgenerated breaking waves and the ambient noise can easily contain components from distant sources (i.e., ships) due to the fact that midfrequencies propagate very efficiently in mirrorlike condition of the sea surface.

Comparing LiSAE skill score with the quantification proposed by Anagnostou et al. [44], it is evident that the latter always gets the best results for one class higher than the correct one except for Beaufort F3 and F7. The best performances for the Vagle at al. [43] parameterization were obtained for the midspeed wind values (Beaufort classes F3 and F4).

\section{Conclusions}

LiSAE experiment (June 2011-May 2012) focused on providing reliable estimates of wind and rainfall in the Ligurian basin by means of the investigation of underwater acoustics data. Underwater data were coupled with high resolution in situ meteorological observations provided by the surface buoy of the W1M3A observing system and the weather radar installed on Monte Settepani.

A PAL [44] was installed at about $36 \mathrm{~m}$ depth on board the surface buoy of the W1M3A observatory and results of the analysis of one year of data were discussed.

Rainfall measurements provided by the rain gauge installed on the mast of the buoy were compared to weather 

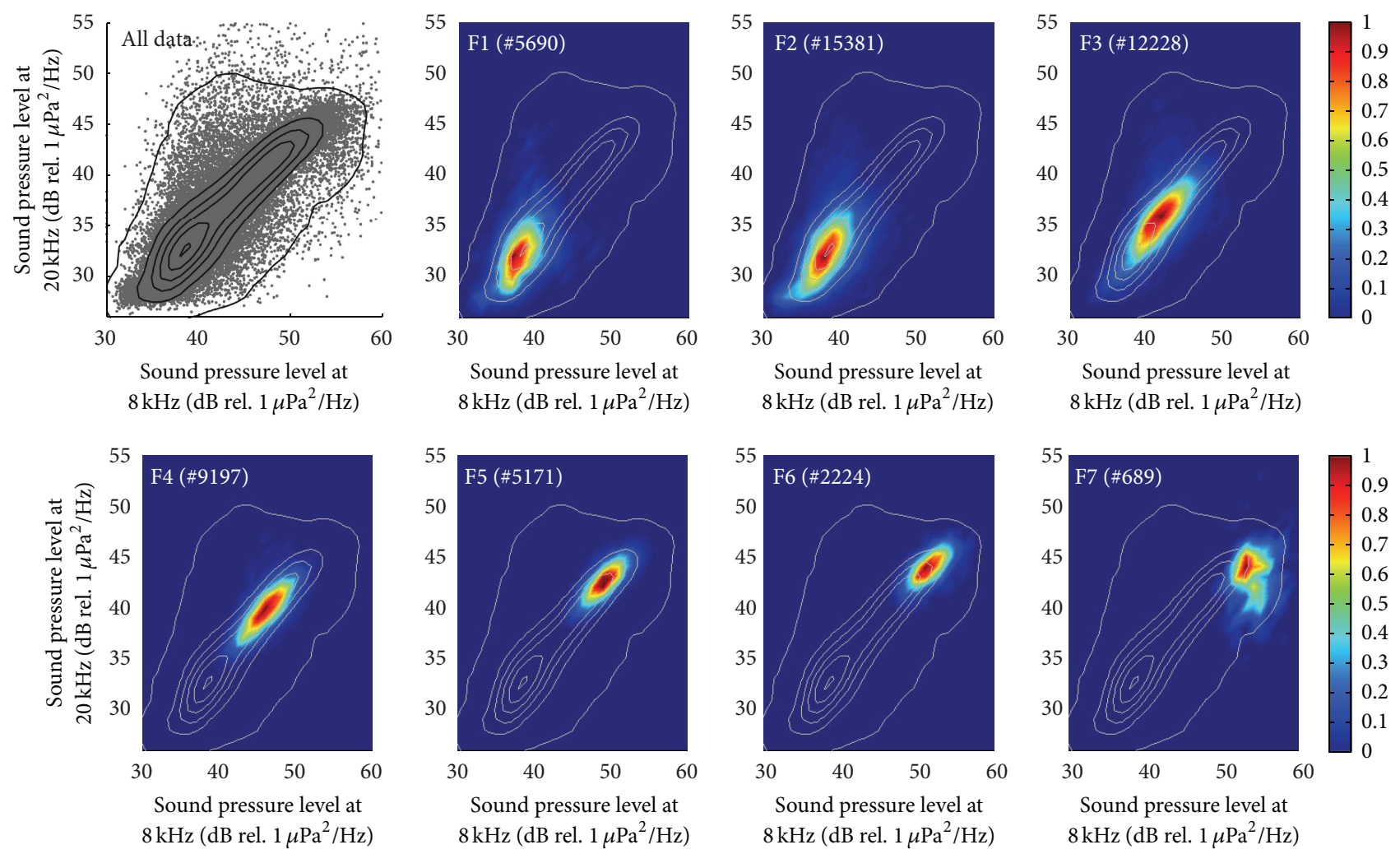

FIGURE 12: Bidimensional distributions of sound pressure levels at $20 \mathrm{kHz}$ and $8 \mathrm{kHz}$. Clusters show relative frequency of the $8-20 \mathrm{kHz}$ pairs for each wind speed class with respect to the contour lines of overall pairs distribution.

radar observations available over the buoy location. The comparison showed a correlation coefficient of 0.68 , a mean absolute error of $0.07 \mathrm{~mm} / \mathrm{h}$, and a mean square error of $0.82 \mathrm{~mm} / \mathrm{h}$.

Two heavy rainfall episodes occurred during the experiment: on the 25th of October 2011 and between the 4th and 5 th of November 2011 in the vicinity of La Spezia and Cinque Terre and in the city of Genoa, respectively, when two floods caused damages and loss of human lives.

With respect to past experiments, the availability of pairs of high resolution meteorological (wind speed and rain) observations and acoustical samples collected simultaneously greatly improved the validation of PAL estimates and allowed the development of new algorithms for the quantification of wind speed and rainfall rate, separately.

Results confirmed that PAL detection algorithms developed by Ma and Nystuen [18] and applied by Anagnostou et al. $[19,44]$ for Atlantic Ocean and Greek seas provided a very good detection of rainfall events also in the Ligurian Sea. This suggested that the use of combinations of acoustic spectral levels at peculiar frequencies and spectral slopes calculated as the least-square fit to sound pressure levels over selected frequency band depending of the type of rainfall can be applied in different basins to detect rainfall episodes.

The application of PAL quantitative algorithms developed by Ma and Nystuen [18] and used by Anagnostou et al. [19, 44] to the LiSAE dataset showed systematic errors of underestimation of drizzle and rain events and overestimation of heavy rain episodes. Thus, a new algorithm was developed to minimize the error and results showed a good agreement between rainfall estimates calculated with the new algorithm and in situ observations underlining the skill of PAL to reproduce the dynamics of rainfall over the buoy location even with very different wind conditions.

Wind speed analysis exhibited a good correspondence between anemometer measurements and acoustic estimates using both relationships introduced by Vagle et al. [43] and Anagnostou et al. [44] with a high correlation of more than 90\%; nonetheless a tendency to overestimate low wind speeds and to underestimate high wind speeds and a systematic overestimation of wind speed was observed applying Vagle et al. [43] and Anagnostou et al. [44] relationships, respectively.

To enhance the performance of wind speed quantification algorithms, a new formulation was proposed. Subdividing wind intensities according to Beaufort scale, the proposed algorithm showed an improvement for all classes except for the F1 class and this is consistent with the fact that noise produced by weak wind speed is too low to be detected.

Results showed that for wind speeds belonging to class greater than F3, the maximum error was slightly above $1 \mathrm{~m} / \mathrm{s}$ (about 20\%) while the overestimation was up to $48 \%$ in $\mathrm{F} 6$ and F7 classes when using the parameterization proposed by Vagle et al. [43] and Anagnostou et al. [44]. 

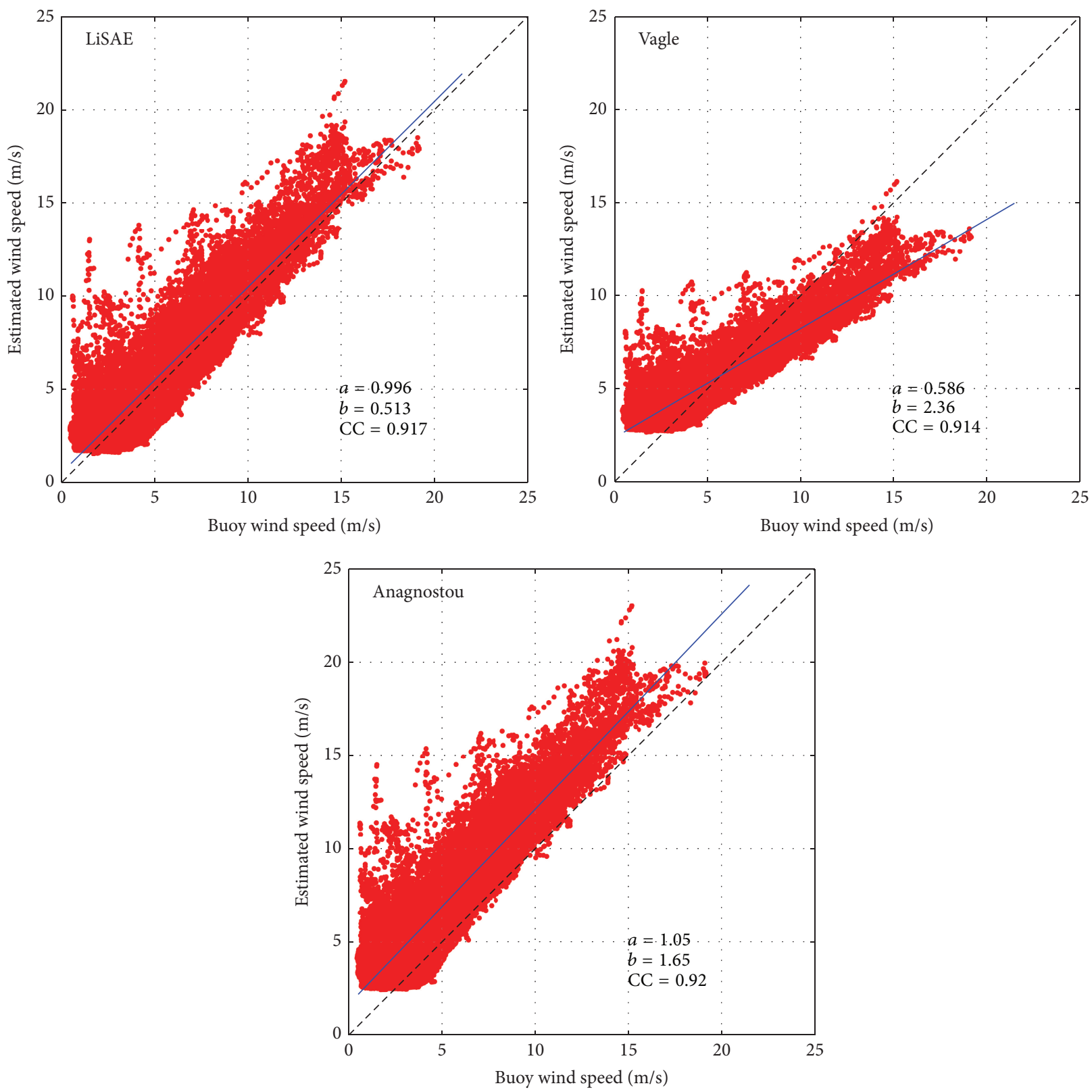

FIGURE 13: Scatter diagram of estimated versus buoy measured wind speed for three algorithms: LiSAE, Vagle, and Anagnostou, respectively. Dashed lines correspond to the 1:1 relationship, whereas solid lines are the linear least square fit to the data described by coefficients $a$ and $b$. The correlation coefficient is indicated by CC.

LiSAE experiment confirmed the use of PALs for obtaining, after a calibration in order to take into account the specific characteristics of the deployment, accurate measurements of wind and rainfall rates at sea that are difficult to acquire on long-term basis without using platforms or buoys equipped with rain gauge and anemometer.

PAL demonstrated also its capability of providing near real-time information about storms at sea that can be potential dangerous on land.

Thus, PAL embedding the proposed data processing algorithms installed on surface buoys or ARGO floats can be very useful to be integrated into early warnings system in the Ligurian basin where quite regularly floods occur during autumn in the northwestern Mediterranean Sea coastal areas of Italy and France Riviera. LiSAE experiment is still ongoing and the latest acquired data will be used for further analysis on the parameterization of both wind and precipitation and new tests will be carried out to improve the capability of PAL to distinguish a more complete set of different sources of oceanic noise.

\section{Conflict of Interests}

The authors declare that there is no conflict of interests regarding the publication of this paper. 

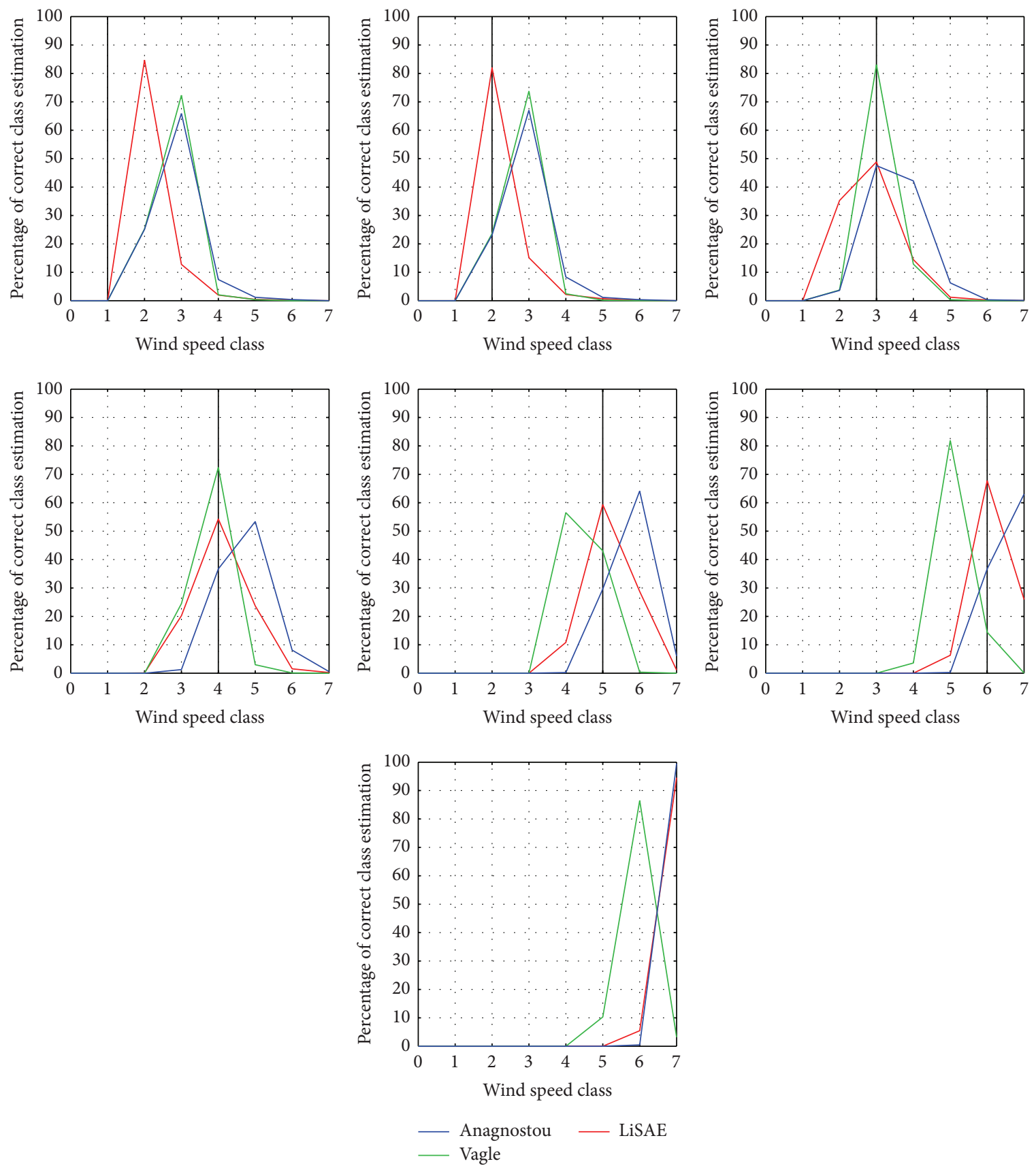

FIgURE 14: Normalized skill score for the three different parameterizations (LiSAE, Vagle, and Anagnostou) for the wind speed classes F1 to F7. The vertical line identifies the correct class.

\section{Acknowledgments}

The research leading to these results has received part of the funding from the European Community's Seventh Framework Programme FP7/2007-2013 under the Grant Agreement no. 287600 (PERSEUS), the Flagship Project RITMARE funded by the Italian Ministry of Education, University and Research, and the 2013 Short-Term Mobility Programme supported by the National Research Council of Italy. The authors would like to acknowledge the contribution of the Agenzia Regionale per la Protezione Ambientale Liguria
(ARPAL) that jointly operates the radar system with ARPA Piemonte for providing part of the Monte Settepani data.

\section{References}

[1] G. M. Wenz, "Acoustic ambient noise in the ocean: spectra and sources," Journal of Acoustics Society of America, vol. 34, no. 12, pp. 1936-1956, 1962.

[2] National Research Council, Committee on Potential Impacts of Ambient Noise in the Ocean on Marine Mammals, The National Academies Press, Washington, DC, USA, 2003. 
[3] N. Zampoukas, H. Piha, E. Bigagli, N. Hoepffner, G. Hanke, and A. C. Cardoso, "Monitoring for the marine strategy framework directive: requirements and options," Tech. Rep., Joint Research Centre, Institute for Environment and Sustainability, 2012.

[4] D. Ross, "On ocean underwater ambient noise," Acoustic Bulletin, vol. 18, pp. 5-8, 1993.

[5] M. P. Johnson and P. L. Tyack, "A digital acoustic recording tag for measuring the response of wild marine mammals to sound," IEEE Journal of Oceanic Engineering, vol. 28, no. 1, pp. 3-12, 2003.

[6] F. K. Duennebier, D. W. Harris, J. Jolly et al., "HUGO: the Hawaii undersea geo-observatory," IEEE Journal of Oceanic Engineering, vol. 27, no. 2, pp. 218-227, 2002.

[7] J. Aguzzi, A. Mànuel, F. Condal et al., "The new seafloor observatory (OBSEA) for remote and long-term coastal ecosystem monitoring," Sensors, vol. 11, no. 6, pp. 5850-5872, 2011.

[8] P. Favali, F. Chierici, G. Marinaro et al., "NEMO-SN1 abyssal cabled observatory in the Western Ionian sea," IEEE Journal of Oceanic Engineering, vol. 38, no. 2, pp. 358-374, 2013.

[9] L. Zedel, L. Gordon, and S. Osterhus, "Ocean Ambient Sound Instrument System: acoustic estimation of wind speed and direction from a subsurface package," Journal of Atmospheric and Oceanic Technology, vol. 16, no. 8, pp. 1118-1126, 1999.

[10] R. Vakkayil, H. C. Graber, and W. G. Large, "Oceanic winds estimated from underwater ambient noise observations in SWADE," in Proceedings of the MTS/IEEE Conference on "Prospects for the 21st Century" (OCEANS '96), vol. 1, pp. 45-51, September 1996.

[11] E. Amitai, J. A. Nystuen, E. N. Anagnostou, and M. N. Anagnostou, "Comparison of deep underwater measurements and radar observations of rainfall," IEEE Geoscience and Remote Sensing Letters, vol. 4, no. 3, pp. 406-410, 2007.

[12] G. D. Quartly, T. H. Guymer, K. G. Birch, J. Smithers, K. Goy, and I. Waddington, "Listening for rain: theory and practice," in Proceedings of the 5th European Conference on Underwater Acoustics, pp. 723-728, Lyon, France, 2000.

[13] T. Guymer, G. Quartly, and K. Birch, "Use of ambient sound measurements in an integrated system for ocean monitoring," Gayana, vol. 68, no. 2, pp. 266-271, 2004.

[14] B.-C. Kim and B. K. Choi, "Variation of underwater ambient noise observed at IORS station as a pilot study," Ocean Science Journal, vol. 41, no. 3, pp. 175-179, 2006.

[15] M. A. McDonald, J. A. Hildebrand, S. M. Wiggins, and D. Ross, "A 50 year comparison of ambient ocean noise near San Clemente Island: a bathymetrically complex coastal region off Southern California," Journal of the Acoustical Society of America, vol. 124, no. 4, pp. 1985-1992, 2008.

[16] J. A. Nystuen, "Listening to raindrops from underwater: an acoustic disdrometer," Journal of Atmospheric and Oceanic Technology, vol. 18, no. 10, pp. 1640-1657, 2001.

[17] J. A. Nystuen, M. J. Mcphaden, and H. P. Freitag, "Surface measurements of precipitation from an ocean mooring: the underwater acoustic log from the South China sea," Journal of Applied Meteorology, vol. 39, no. 12, pp. 2182-2197, 2000.

[18] B. B. Ma and J. A. Nystuen, "Passive acoustic detection and measurement of rainfall at sea," Journal of Atmospheric and Oceanic Technology, vol. 22, no. 8, pp. 1225-1248, 2005.

[19] M. N. Anagnostou, J. A. Nystuen, E. N. Anagnostou, E. I. Nikolopoulos, and E. Amitai, "Evaluation of underwater rainfall measurements during the Ionian sea rainfall experiment," IEEE Transactions on Geoscience and Remote Sensing, vol. 46, no. 10, pp. 2936-2946, 2008.
[20] S. C. Riser, J. Nystuen, and A. Rogers, "Monsoon effects in the Bay of Bengal inferred from profiling float-based measurements of wind speed and rainfall," Limnology and Oceanography, vol. 53, no. 5, pp. 2080-2093, 2008.

[21] R. Lampitt and L. Cristini, "Fixed point Open Ocean Observatory network (FixO3): multidisciplinary observations from the air-sea interface to the deep seafloor," Geophysical Research Abstracts, vol. 16, EGU2014-3696, 2014.

[22] M. Astraldi and G. P. Gasparini, "The seasonal characteristics of the circulation in the north Mediterranean basin and their relationship with the atmospheric-climatic conditions," Journal of Geophysical Research, vol. 97, no. 6, pp. 9531-9540, 1992.

[23] S. Pensieri, R. Bozzano, and M. E. Schiano, "Comparison between QuikSCAT and buoy wind data in the Ligurian Sea," Journal of Marine Systems, vol. 81, no. 4, pp. 286-296, 2010.

[24] A. M. Sempreviva, M. E. Schiano, S. Pensieri et al., "Observed development of the vertical structure of the marine boundary layer during the LASIE experiment in the Ligurian Sea," Annales Geophysicae, vol. 28, no. 1, pp. 17-25, 2010.

[25] I. F. Trigo, T. D. Davies, and G. R. Bigg, "Objective climatology of cyclones in the mediterranean region," Journal of Climate, vol. 12, no. 6, pp. 1685-1696, 1999.

[26] A. Jansa, A. Genoves, and J. A. Garcia-Moya, "Western Mediterranean cyclones and heavy rain. Part 1: numerical experiment concerning the Piedmont flood case," Meteorological Applications, vol. 7, no. 4, pp. 323-333, 2000.

[27] K. Nittis, C. Tziavos, R. Bozzano et al., "The M3A multi-sensor buoy network of the Mediterranean Sea," Ocean Science, vol. 3, no. 2, pp. 229-243, 2007.

[28] N. Pinardi, I. Allen, E. Demirov et al., "The Mediterranean ocean forecasting system: first phase of implementation (19982001)," Annales Geophysicae, vol. 21, no. 1, pp. 3-20, 2003.

[29] L. Cavaleri and E. Mollo-Christensen, "Wave response of a spar buoy with and without a damping plate," Ocean Engineering, vol. 8, no. 1, pp. 17-24, 1981.

[30] P. Davini, R. Bechini, R. Cremonini, and C. Cassardo, "Radarbased analysis of convective storms over Northwestern italy," Atmosphere, vol. 3, no. 1, pp. 33-58, 2012.

[31] J. Testud, E. le Bouar, E. Obligis, and M. Ali-Mehenni, "The rain profiling algorithm applied to polarimetric weather radar," Journal of Atmospheric and Oceanic Technology, vol. 17, no. 3, pp. 332-356, 2000.

[32] B. Vignal, H. Andrieu, and J. D. Creutin, "Identification of vertical profiles of reflectivity from volume scan radar data," Journal of Applied Meteorology, vol. 38, no. 8, pp. 1214-1228, 1999.

[33] J. Joss and A. Waldvogel, "A method to improve the accuracy of radar measured amounts of precipitation," in Proceedings of the 14th Conference on Radar Meteorology, pp. 237-238, American Meteorological Society, Tucson, Ariz, USA, November 1970.

[34] Campbell Scientific, Gill Instruments WindSonic Two Dimensional Sonic Anemometer, Instruction Manual, Revision 3/07, 2004-2007.

[35] L. Tuomaala, "New possibilities for weather measurement," Vaisala News, vol. 166, 2004.

[36] H. C. Pumphrey, L. A. Crum, and L. Bjorno, "Underwater sound produced by individual drop impacts and rainfall," Journal of Acoustics Society of America, vol. 85, no. 4, pp. 1518-1526, 1989.

[37] H. Medwin, J. A. Nystuen, P. W. Jacobus, L. H. Ostwald, and D. E. Snyder, "The anatomy of underwater rain noise," Journal of the Acoustical Society of America, vol. 92, no. 3, pp. 1613-1623, 1992. 
[38] J. A. Nystuen, "An explanation of the sound generated by light rain in the presence of wind," in Natural Physical Sources of Underwater Sound, B. R. Kerman, Ed., pp. 659-668, Kluwer Academic, 1993.

[39] J. A. Nystuen, E. Amitai, E. N. Anagnostou, and M. N. Anagnostou, "Spatial averaging of oceanic rainfall variability using underwater sound: ionian sea rainfall experiment 2004," Journal of the Acoustical Society of America, vol. 123, no. 4, article 1952, 2008.

[40] ARPAL, "Uno tsunami venuto dai monti," Technical Report of Meteo-Hydrological Event, Agenzia Regionale per la Protezione dell'Ambiente Ligure, Genoa, Italy, 2012.

[41] ARPAL, Technical Report of Meteo-Hydrological Event, Agenzia Regionale per la Protezione dell'Ambiente Ligure, Genoa, Italy, 2012.

[42] R. Bechini, R. Cremonini, E. Gorgucci, and L. Baldini, "Dualpol radar calibration and correction of the bias introduced by non uniform radome wetting," in Proceedings of the 4th European Conference on Radar in Meteorology and Hydrology (ERAD '06), Barcelona, Spain, 2006.

[43] S. Vagle, W. G. Large, and D. M. Farmer, "An evaluation of the WOTAN technique of inferring oceanic winds from underwater ambient sound," Journal of Atmospheric and Oceanic Technology, vol. 7, no. 4, pp. 576-595, 1990.

[44] M. N. Anagnostou, J. A. Nystuen, E. N. Anagnostou, A. Papadopoulos, and V. Lykousis, "Passive aquatic listener (PAL): an adoptive underwater acoustic recording system for the marine environment," Nuclear Instruments and Methods in Physics Research, Section A: Accelerators, Spectrometers, Detectors and Associated Equipment, vol. 626-627, supplement, pp. S94-S98, 2011. 

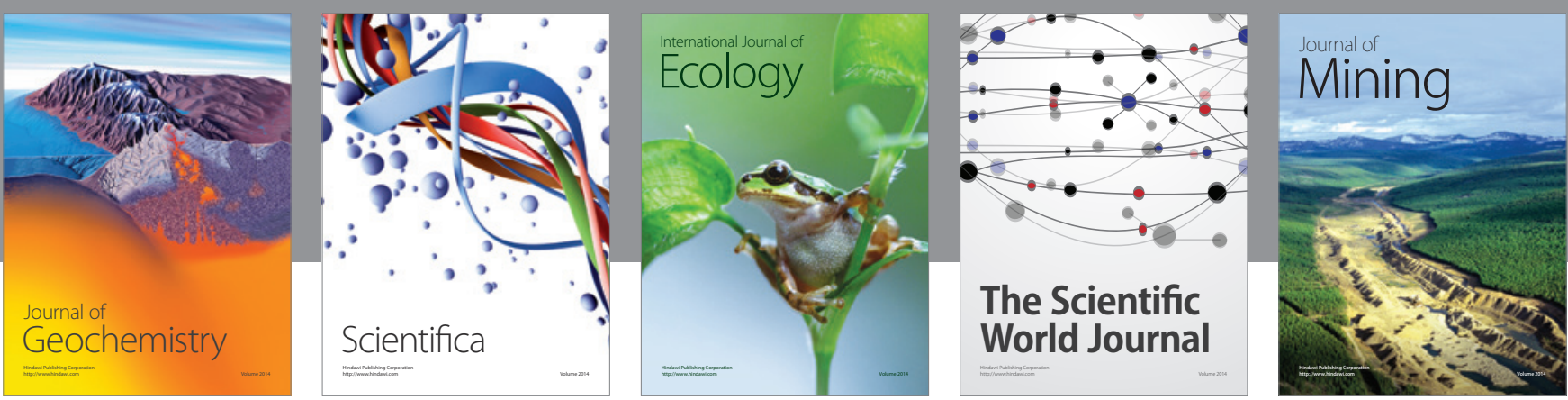

The Scientific World Journal
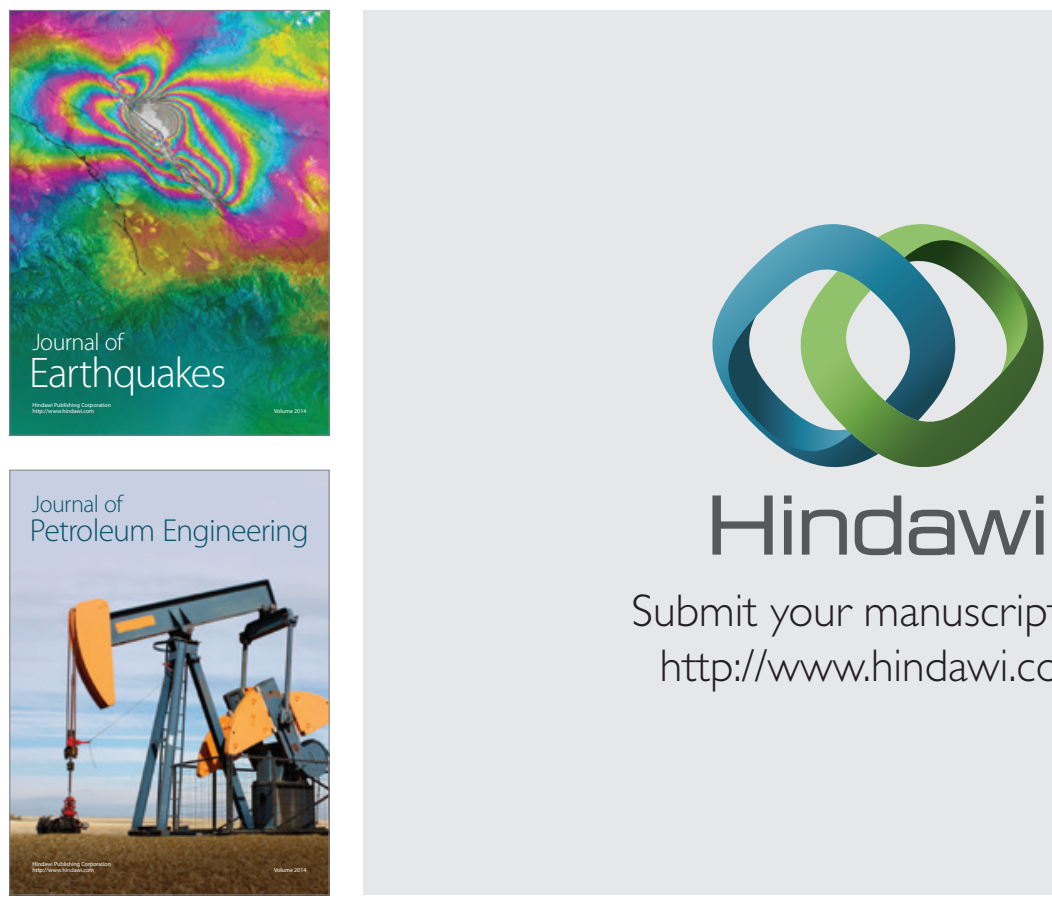

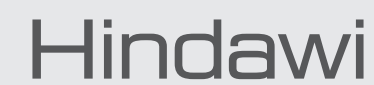

Submit your manuscripts at

http://www.hindawi.com
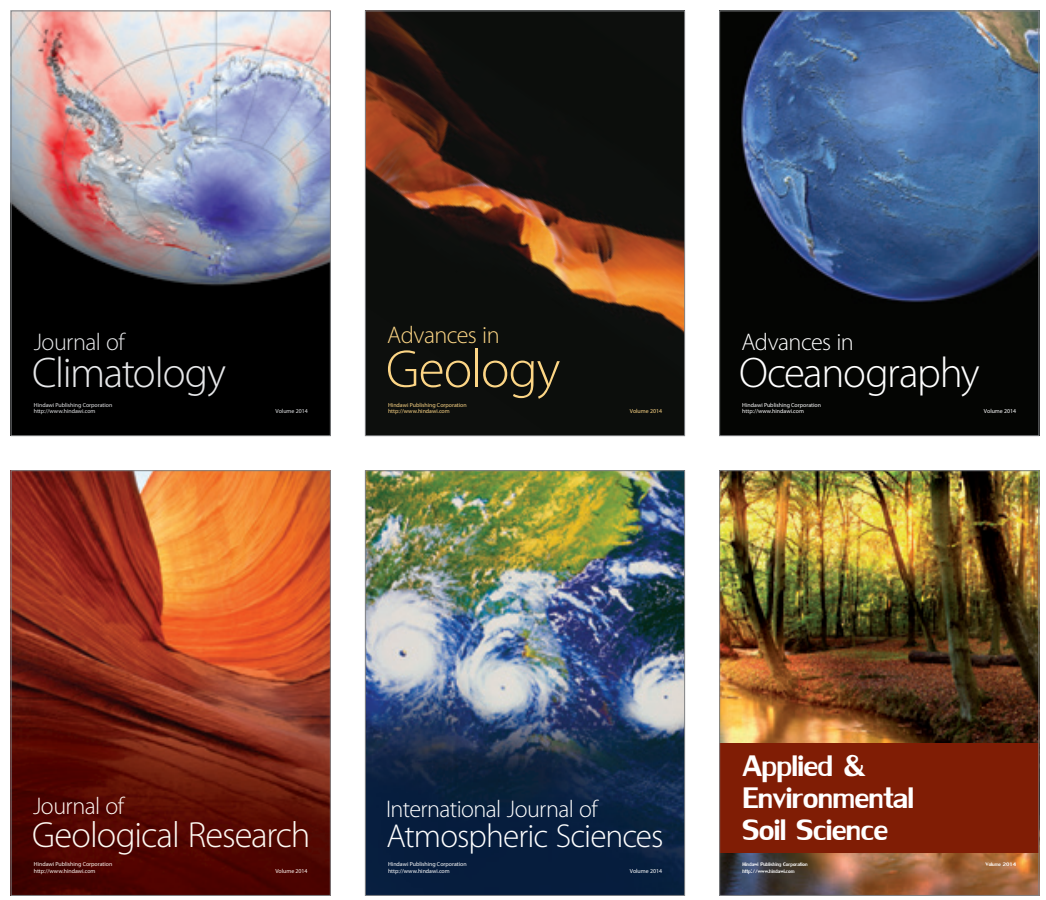
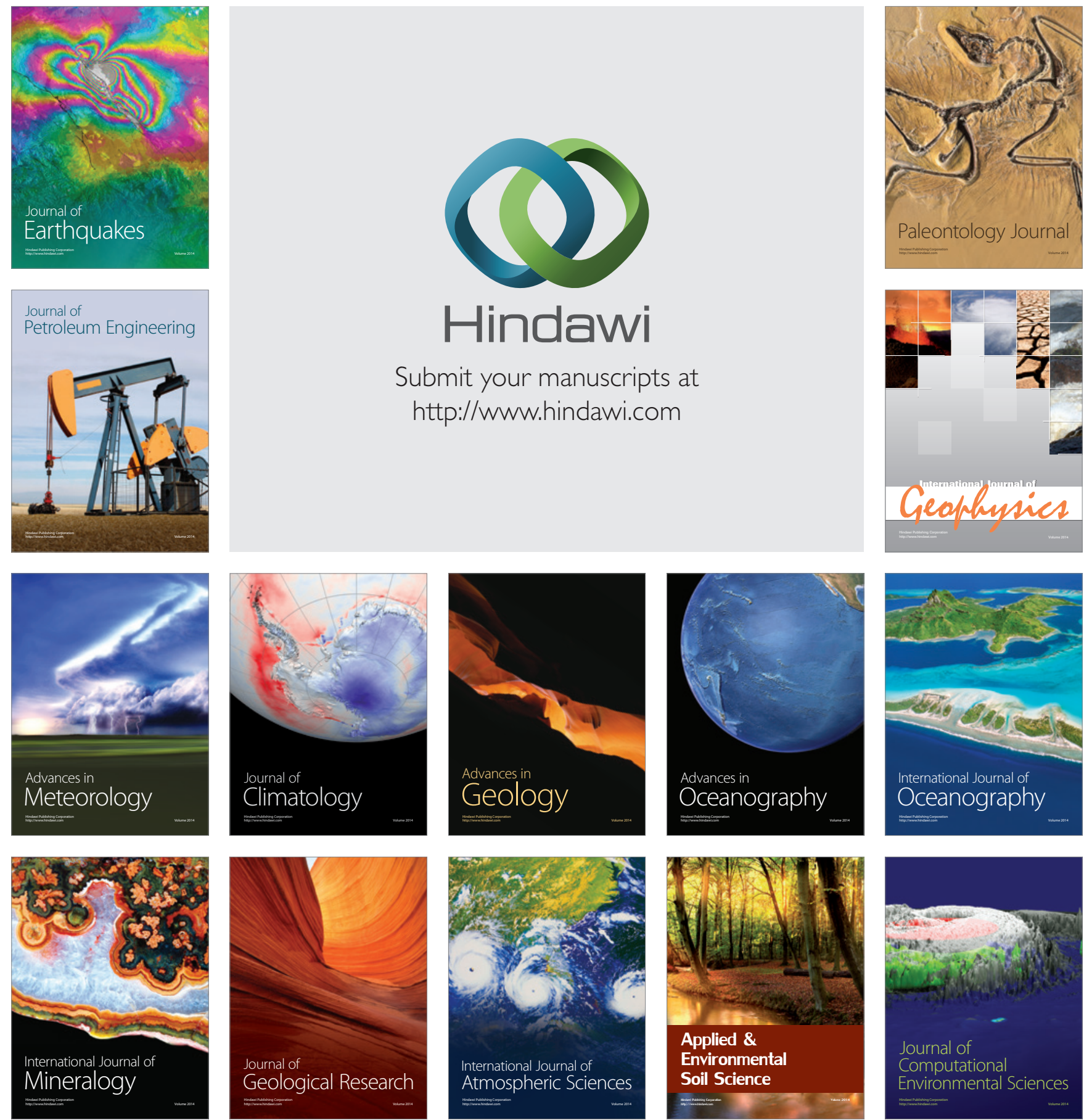